Elena A. Murzina

Marina S. Shemyakina

\title{
TAX SECURITY MANAGEMENT OF A PUBLIC ENTITY
}

The reported study was funded by RFBR, project number 19-010-00620 
Elena A. Murzina

Marina S. Shemyakina

TAX SECURITY MANAGEMENT OF A PUBLIC ENTITY

Monograph

The reported study was funded by RFBR, project number 19-010-00620

B\&M Publishing

San Francisco, California, USA

2021 
Reviewers:

Alexey V. Burkov, Doctor of sciences Economics, Professor, Mari state university, Russia.

Ruslan V. Pshenichnov, Candidate of economic sciences, Head of the Partner Sales Channel Development Service, Rosselkhozbank Joint Stock Company, Russia.

Murzina E.A., Shemyakina M.S. (2021). Tax security management of a public entity: monograph, B\&M Publishing, San Francisco. $110 \mathrm{pp}$.

The monograph is devoted to the study of the concept of tax security management of a public legal entity. The concept is built on the interconnection of three main elements: analysis, monitoring and regulation. The role of analysis in the control system is determined. Special attention is paid to monitoring. It is proposed to use the method of constructing a heat map as a data visualization tool for monitoring. It is noted that regulation and management decision-making should be carried out taking into account the monitoring data and the main guidelines of the budgetary and tax policy of a public legal entity. The material of the monograph has a practical focus on improving the work of participants in the budgetary process to manage the tax security of a public legal entity on the basis of a risk-oriented approach. The presented material can open up new perspectives for further research. It will be of interest to those who are engaged in the development of methodological support for tax security management.

The reported study was funded by RFBR, project number 19-01000620

Copyright (C) 2021

ISBN 978-1-7363817-6-2

by authors

All rights reserved.

DOI: http://doi.org/10.15350/mJ2021

Published by B\&M Publishing.

For permission to use material from this text, please contact the publisher at

2076 -16th Ave., Suite A,

San Francisco, California 94116, 


\section{TABLE OF CONTENTS}

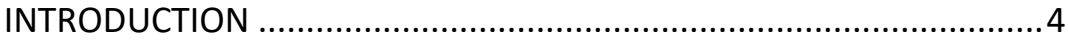

Chapter 1. PROBLEMS OF TAX SECURITY MANAGEMENT OF A

PUBLIC LEGAL ENTITY ............................................................... 7

1.1. The concept of tax security management of a public legal

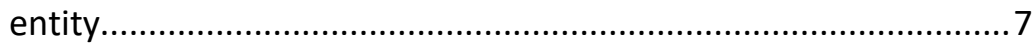

1.2. Tax security of the territory and its provision in the context of the development of the digital economy

1.3. Impact of coronavirus (COVID-2019) on regional tax security:

analytical approaches to assessment

Chapter 2. MONITORING THE TAX SECURITY MANAGEMENT OF THE REGION

2.1. Methodological prerequisites for the organizational monitoring model for use in the tax security system of the region

2.2. Consumption taxes in international classifications

2.3. Organizational model of monitoring in the context of tax security of the region 58

2.4. Monitoring of tax security management of a territory based on a risk-based approach 63

CONCLUSION 68

BIBLIOGRAPHY 86 


\section{INTRODUCTION}

This monograph is devoted to the problems of tax security management. The results obtained during the implementation of the project are comparable to the world scientific level of development of scientific knowledge about the essence of tax potential, tax security of the region and tax risk management, and in a number of aspects surpass the developments of foreign researchers. The theoretical and practical significance of the study is that the results develop the theoretical foundations for the methodological support of multi-level monitoring and management of the tax security of the region, and the system of practical recommendations formulated in the study makes it possible to timely identify risk zones of deviation of tax security indicators from the established "safe" level. correctly identify threats to tax security, make a quick assessment of the identified threats and immediately take measures to ensure an acceptable level of tax security in the region.

Historically, in the world economic science, the topic of tax risks, economic security and tax potential has received wide coverage, but mainly at the level of the formation of the conceptual apparatus and economic and philosophical ideas about these categories. The accumulated amount of knowledge cannot be ignored, but it was insufficient to achieve the goal set in our project. Having studied, among other works on the topic of tax potential, tax risks and economic security Hemlata Rao (1993), Tuan Minh Le, Blanca Moreno-Dodson and Jeep Rojchaichaninthorn (2012), Luky Alfirman (2003), Stefan Brehm 
(2013), we came to the conclusion that a practical assessment of the tax potential should be carried out on the basis of determining its essence as the maximum possible amount of tax revenues of the budgetary system of a particular territory, obtained in the current conditions for the formation of tax bases using the legislatively established tax mechanism.

Foreign authors in their studies in relation to ensuring the economic security of the territory and its economic entities focus on efficiency criteria (economic, social, budgetary) (Sternberg R. (2017), Kadirbeyoğlu, Z., Adaman, F., Özkaynak, B., \& Paker, H. (2017)). For example, Fuller T., Moran P. (2016) distinguishes such a criterion as the significance of government support measures among its recipients. That is, they start from the position that the more economically secure the territory is, the more efficiently the state pursues a policy of economic support for the subjects. Our results indicate that even in conditions of budget deficit and economic instability, tax economic security should provide, along with financial support for business entities, the tax potential of the territory.

In modern foreign works, tax risks are considered separately from the category of "tax security", which is practically not given due attention. The research aspects are different. In some works, tax risks are identified as a factor of sustainable development of territories (Chen W. (2020), Lind Y. (2020), Mosquera Valderrama IJ, Chaisse, J., Choukroune, L., \& Jusoh, S. (2020). scientists (Strauss H. (2020)). research methods of collecting and processing information about tax risks by tax 
administrations in the context of the development of the digital economy.

The results obtained by us supplement the body of the original knowledge of foreign researchers, without duplicating them. So, the problems of assessing the economic component of national security abroad are dealt with by the Center for Strategic and Budgetary Assessments (USA), the Center for a New American Security (USA), the Center for Strategic and International Studies (USA). (Center for Strategic and International Studies, RAND (RAND Corporation), Nanzan University (Japan), Center for Chinese Public Administration Research (China). Foreign studies are characterized by the study of the economic aspect of national security. At the same time, tax security as a component of economic security These organizations pay little attention to the fundamental research of individual scientists and research teams devoted to the methodology of monitoring tax security and the development of a management strategy for this system. 


\section{Chapter 1. PROBLEMS OF TAX SECURITY MANAGEMENT OF A PUBLIC LEGAL ENTITY}

\subsection{The concept of tax security management of a public legal entity}

Tax security management of public law education is necessary to ensure its sustainable development. This process is based on the analysis and monitoring of tax security risks, which are uncertainties of an unfavorable nature that create conditions and form factors of danger to the interests of the state and territory.

The aim of the study is to develop theoretical provisions in terms of creating a concept of tax security management for a public legal entity. To achieve this goal, the following task is defined in the work: to study the process of managing tax security of a public legal entity, taking into account different time horizons, based on a risk-based approach.

The theoretical and methodological basis of the study is the scientific works of Russian and foreign scientists on the problems of methodological support of tax security management of a public legal entity.

In modern foreign works, tax risks are considered separately from the category of "tax security", which is practically not given due attention. The research aspects are different. In some works, tax risks are identified as a factor in the sustainable development of territories (Chen W., 2020; Lind Y., 2020; Mosquera Valderrama IJ, Chaisse, J., Choukroune, L., \& Jusoh, S., 2020. Some scientists 
(Strauss H., 2020) investigate methods of collecting and processing information about tax risks by tax administrations in the context of the development of the digital economy.

Russian scientists examine in detail various aspects of tax security (Bykovskaya Yu.V., Safokhina E.A., 2019; Mironova O.A., 2017; Safokhina E.A., 2019). However, the issue of developing a concept for managing the tax security of public law entities, depending on the level of their budgetary provision and the time horizon of management, remains insufficiently studied.

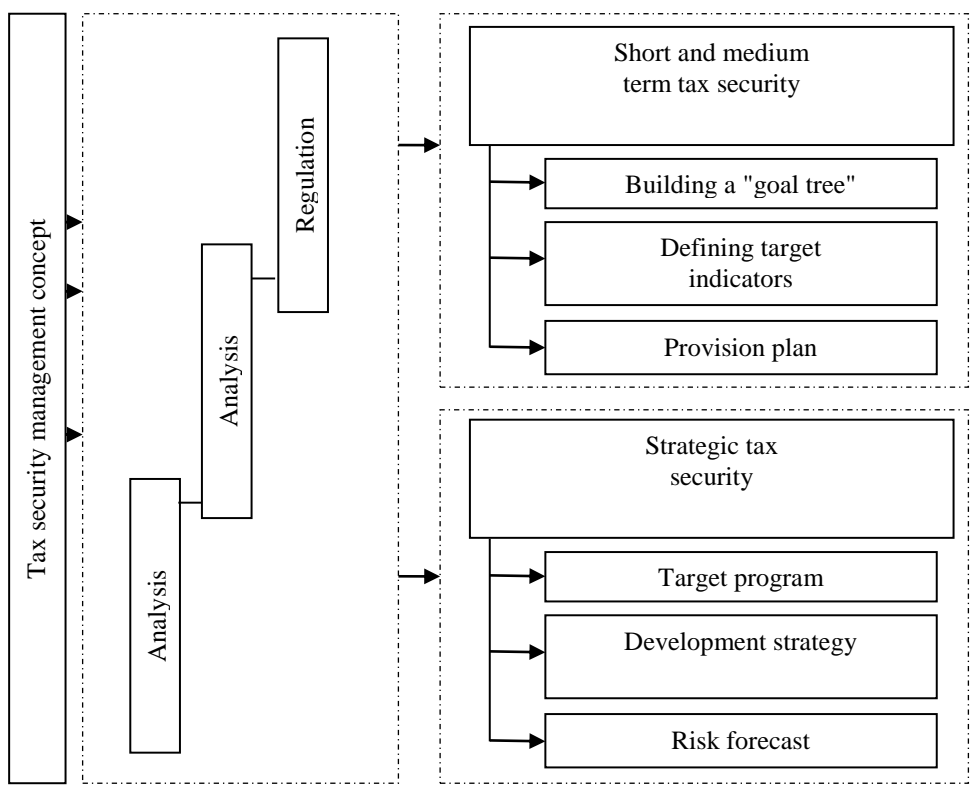

Fig. 1. The concept of tax security management of a public legal entity Source: developed by the author 
The concept of tax security management of a public legal entity developed by us is based on the classical management functions identified by Henri Fayol (H. Fayol, 1923). It is built on the interconnection of three main elements: analysis, monitoring and regulation. Let's consider each of the elements in more detail.

The analysis is carried out within the framework of all tax reporting generated by tax authorities and characterizing the state of the tax system and tax potential, ensuring the sustainable development of a public entity.

One of the functions of the process of ensuring tax security is monitoring - a systematic confirmation that the indicators we have identified in previous studies that characterize the fiscal system correspond to the established "corridors". For a more visual data visualization, it is proposed to use a heat map.

Taking into account the monitoring data and the main guidelines of the budgetary and tax policy of a public legal entity, regulation should be carried out. The regulation is based on a riskbased approach. Thus, indicators that do not correspond to the specified parameters require special attention in order to minimize the threat of lack of tax revenues at all levels of the budget system. Reducing the level of risks, depending on the expected time of their manifestation, should be developed either within the short-term (up to 3 years, which corresponds to the period of budget planning), or within the medium-term (from 3 to 7 years), or within the framework of strategic (over 7 years) provision tax security.

Depending on the time of the risk manifestation, it is proposed to use various tools. So, short-term and medium-term assurance 
of tax security presupposes the construction of a "tree of goals", in accordance with which the corridors of indicators are determined. Depending on different scenarios (pessimistic, optimistic), a plan should be developed to ensure minimization of risks and threats. For strategic support, one should take into account the long-term priorities of a public legal entity, balance planned actions, and predict risks.

Thus, the management of tax security of a public legal entity is an analysis and monitoring of indicators characterizing the state of the tax system, as well as regulation of the set parameters for making managerial decisions.

In this study, we tested one of the elements of the proposed concept - monitoring on the example of the Republic of Mari El.

The Republic of Mari El is a territory with a low level of socioeconomic development. According to the national rating, ASI belongs to the regions with moderate investment attractiveness. Since 2019, it has been one of the 10 lagging regions of Russia, for which individual development plans have been developed. The main driver of economic growth of the approved individual plan, in our opinion, is the development of high-tech industries that are part of the radio electronics cluster and make it possible to reduce the dependence of the domestic market on exports. The implementation of these goals will allow expanding the tax base of the region, strengthening the tax potential and reducing one of the main threats to tax security - the insufficient formation of tax potential and the provision of tax revenues to budgets of all levels. Reducing this threat is also possible with constant monitoring of 
tax risks and prompt management decisions based on their assessment.

The monitoring included 5 groups of risks identified by us:

$\mathrm{R} 1$ - risks of a fall in the level of tax revenues in relation to the planned indicators;

R2 - risks of insufficient formation of the tax base and assessment of tax potential;

R3 - risks of increasing the level of tax arrears in the region;

R4- risks of reducing the efficiency of tax control;

R5 - risks of a critical situation in the socio-economic development of the region.

For each group, calculations were made of characterizing indicators (growth / decline rates). A heat map was used as a data visualization tool. The results are shown in Figure 2.

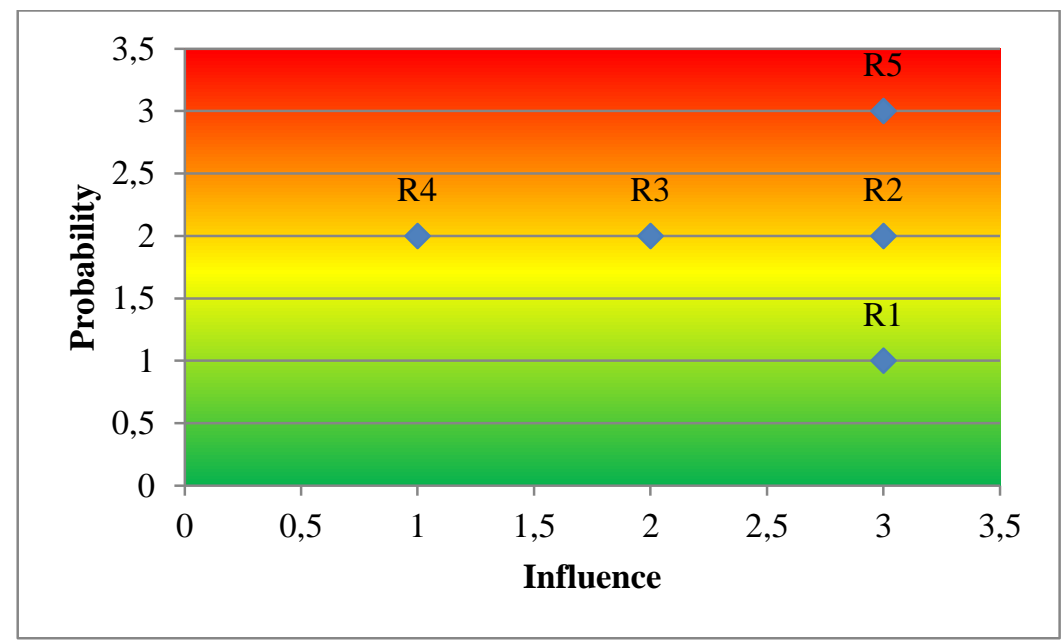

Fig. 2. Heat map of tax security risks in the Republic of Mari El. Source: developed by the author 
The abscissa shows the influence of risk groups on the final result - sustainable development of the tax system of the Republic of Mari El. The ordinate is the probability with which, in our opinion, these risk groups are possible to manifest. The gradient of the fill from green to red, which characterizes the onset of the most probable risks.

The analysis showed that two groups deserve the most attention in terms of risk minimization: the risks of a critical situation in the socio-economic development of the region and the risks of insufficient formation of the tax base and assessment of the tax potential. This necessitates constant monitoring of indicators characterizing these risk groups. In 2022, the Federal Tax Service of Russia plans to put into commercial operation a new analytical complex "Tax Potential", which will be mainly used to forecast tax revenues of the budget. However, already now we can say that the potential for the implementation of this project is much wider: using the analytical complex it will be possible not only to draw up tax passports (financial profiles) of taxpayers, but also to work efficiently in the tax risk monitoring system, including carrying out a factor-based analysis receipts to the budgetary system. This will increase the efficiency of tax security management of a public entity. 


\subsection{Tax security of the territory and its provision in the context of the development of the digital economy}

The most significant challenges from the point of view of the scientific and technological development of the Russian Federation are the exhaustion of opportunities for Russia's economic growth against the background of the formation of the digital economy, as well as new external threats to national security and the strengthening of their relationship with internal threats to national security. The search for effective tools for answering them is an urgent direction of modern scientific research.

One of the directions of the national program "digital economy of the Russian Federation" is the digitalization of public administration. The passport of this program states that by December 31, 2024, a digital platform must be formed for interaction in the field of strategic management in order to coordinate the actions of participants in strategic planning at all levels of government in achieving strategic priorities. It should be noted that the digital economy is primarily a data economy. Digital data is a key factor of production in all spheres of socio-economic activity, which increases the country's competitiveness, the quality of life of citizens, ensures economic growth and national sovereignty. At the same time, strategic planning, in our opinion, is not possible without analyzing such data, which, in turn, are also involved in assessing the tax security of public legal entities.

The development of a state is impossible without ensuring its national security, one of which is tax security. This allows you to 
preserve sovereignty, territorial integrity, the ability to respond to emerging threats and threats. At present, the Russian Federation is confidently moving along the path of digitalization. The implementation of the relevant provisions of the National Program "Digital Economy of the Russian Federation" requires a study of threats to economic security (as an integral part of the country's national security) precisely from the standpoint of introducing digital technologies.

In this regard, the verification of the fundamental hypothesis regarding the increase in the level of national security in connection with the digitalization of the country seems to be very relevant. Including research and forecasting the dynamics of the main and secondary situational risks and assessing the influence of factors that form threats to tax security of the territory in connection with the use of digital technologies of tax administration.

The theoretical and practical aspects of the essence of tax security were considered with varying degrees of completeness in the works of R.S. Bekova, B.V. Vorontsova, V.A. Dvoryankova, A.N. Litvinenko, O. A. Mironova. E.A. Oleinikova, V.P. Ochelyko, N.A. Pimenova, V.K. Senchagova, I. Yu. Timofeeva, T.Yu. Feofilova, A.A. Felyust, A.A. Tsviliy-Buklanova, E.V. Chernikova and others. The main areas of research related to tax security are currently the issues of its provision at the enterprise level. However, many problematic issues still require reflection and search for new scientific approaches. Thus, insufficient attention has been paid to tax security as a subsystem of economic security at the level of the state, region and its municipalities in existing studies. The topical 
issue of assessing tax security in the context of the development of the digital economy, as well as developing a strategy for ensuring it, remains poorly understood.

In the works of scientists from other countries, the tax component is mainly investigated in the framework of ensuring the economic security of the territory. For example, the Institution for Social and Policy Studies (New Haven) calculates the index of economic security. Another approach is to study tax security not at the state level, but at the level of an economic entity. Thus, the US IRS views tax security from the perspective of a taxpayer and is based on "improved authentication procedures, improved information exchange, increased cybersecurity and increased subject and population coverage."

It should be noted that the methodology of ensuring tax security of the territory in the context of the development of the digital economy is practically not studied by modern tax scientists. However, the determination of effective methods to ensure it and identify threats is one of the conditions for long-term balance of budgets and the development of a long-term budget strategy, as well as increasing the effectiveness of regulation of the financial and budgetary sphere. This led to the identification of the main areas of research for the further development of a methodology for ensuring tax security in the context of the development of the digital economy. In our opinion, these should include:

1.Blockchain technology. Big data.

A methodology for identifying and leveling threats to tax security of a territory should be based on an analysis of the mechanism for 
using blockchain technologies as a tool for its provision, as well as on the possibilities of analytical work of the Federal Tax Service of Russia with Big data accumulated in the AIS tax and ASK VAT systems. At the same time, the development of analytical support - the development of methodological tools for assessing indicators of tax security of a territory, should be carried out on the basis of BIG DATA accumulated by tax authorities, contained in information analytical systems, and also obtained as a result of interdepartmental exchange.

On the business side, an ecosystem of analytical products for processing Big data is just being formed, as for the state, such a system has already been created and is in the hands of the tax authorities. This necessitates the search for new effective directions for the use of existing big data and the development of innovative tools for their processing. This is a fairly large array of data that requires processing. On the one hand, the tax authority receives information about the structure of consumption of goods and services both in the context of generalized groups: food, clothing, etc., and in the context of names: brand, product, etc. On the other hand, we can estimate the expenses of individuals by comparing them with the personal income tax base and try to estimate the latent (hidden) tax base.

2. Risk assessment and identification of external and internal threats to tax security of the territory in the context of digitalization of tax administration data.

Today, the processing of big data accumulated by the Federal Tax Service is carried out, among other things, in the software product of ASK "VAT". Thanks to the introduction of this system, the tax 
authorities can identify the risks that form one of the threats to the tax security of the territory - the insufficient formation of the tax potential of a public legal entity due to the withdrawal of value added tax from the budget for dubious transactions. The specified software product distributes all taxpayers who submitted tax returns into three groups according to the "traffic light" principle: high (red), medium (yellow), low (green) risks.

This distribution occurs automatically based on a large number of criteria incorporated into the system. At the same time, an analysis of the chain of counterparties is carried out in order to find gaps in the payment of VAT to the budgetary system.

High-quality analytical work allows you to assess the degree of "cleanliness" of the administered environment, to identify risks and assess the threats to tax security of a public legal entity. It should be noted that the Federal Tax Service has great capabilities for implementing advanced Big data analytics. This is due, first of all, to the fact that in real time an array of data is formed that unites information obtained from the online cash register, product labeling, the population register and the register of civil registry offices. The use of various modern digital technologies and methods and their gradual improvement will allow in the future to significantly reduce the shadow sector or get rid of it altogether by increasing the transparency of taxpayers' performance indicators.

3. Development of an economic and mathematical model of tax security of the region and its municipalities.

The development should be carried out on the basis of the obtained results of the generalized model of tax security with the 
definition of the role of its main components in the values of the basic parameters of risks and associated adverse consequences, as well as the construction of scenarios of adverse events and quantitative assessment of risks through the parameters of the main initiating and damaging factors.

4. Development of a strategy for ensuring the tax security of the region, taking into account the identified risks that form the threat of insecurity of budgets with tax revenues.

The development of a strategy for tax security of the territory in the context of the development of the digital economy, in our opinion, should be carried out taking into account:

- identifying the main trends in the formation and development of Russian tax policy, taking into account the security of a public legal entity in the context of the development of the digital economy;

- analysis of internal and external threats to tax security of a public legal entity;

- development of methodological support and strategy for tax security of the region and its municipalities.

5. Development of an index of tax security of the territory for the purpose of its constant monitoring based on Big data analytics accumulated by tax authorities.

In our opinion, the tax security index is an indicator that can be used to assess the state of stability of a public-legal entity in order to check the presence of a threat of non-provision of budgets of all levels with tax revenues. This determines the choice of indicators for such an assessment, which is based on the methodology for analyzing hierarchies and calculating the integral indicator. 
An integral assessment of tax security can be carried out in the context of 5 blocks of indicators we have identified:

1. Indicators characterizing the flow of taxes and fees into the budgetary system:

The growth rate of tax collection, the growth rate of tax revenues.

2. Indicators characterizing the state of the tax base of the territory:

The growth rate of the amount of lost taxes due to the use of incentives, the growth rate of the tax base

3. Indicators characterizing tax arrears:

Growth ratio of debt / settled debt to the budget.

4. Indicators characterizing the results of tax control:

The coefficient of effectiveness of inspections, an indicator of the proportion of additionally accrued amounts of tax payments to the total volume of tax revenues.

5. Indicators characterizing the socio-economic situation in the region:

GRP, Consumer Price Index, Tax burden on GRP

In each block, no more than 3-4 characteristic indicators should be considered, quantifying their changes. Moreover, for such an analysis, growth or gain factors can be calculated. After that, it is necessary, on the basis of pairwise comparison of the groups of indicators, to select the weight coefficients and determine the aggregate indicator of the group. The sum of the summary indicators of each block we have identified determines the integral indicator of the tax security of the territory. After that, based on the analysis of the obtained value and its comparison 
with the corridor of values of the integral indicator, a conclusion should be drawn about the state of tax security of a public legal entity.

The scientific significance of the study of the directions indicated in the chapter lies in a comprehensive study of tax security as a component of the national security of the country, as well as in the development of methodological foundations for ensuring (assessment, management, monitoring) of tax security at the level of various territorial entities in the context of the development of the digital economy. The solution to this problem will allow:

First, timely identify risk zones of deviation of tax security indicators from the established "safe" level,

Second, to correctly identify threats to tax security,

Third, make a quick assessment of the identified threats and, fourth, take immediate steps to ensure an acceptable level of tax security. 


\subsection{Impact of coronavirus (COVID-2019) on regional tax security: analytical approaches to assessment}

The complex epidemiological situation that is developing in Russia and in the world imposes new and increased requirements on representatives of the business communities: organizations and individual entrepreneurs. They are entrusted not only with the responsibility for the correct calculation and timely payment of taxes and fees, the calculation and payment of insurance contributions to the Pension Fund of the Russian Federation, the Social Insurance Fund, the Mandatory Medical Insurance Fund, but also the obligation to preserve jobs and timely payment of wages to employees.

We have made an attempt to present approaches to the implementation of state support for business entities. State support cannot be provided to everyone in an equal amount; it must have not only targeted, but also personalized character. First of all, state support should ensure stabilization or reduction of negative dynamics of profits and taxes paid. The entrepreneur is provided with support to maintain the size of the staff, to prevent dismissal of employees due to business downtime. At the same time, this assistance should have a positive effect not only from the standpoint of maintaining the number of employees, but also to provide conditions for the payment of insurance premiums, that is, the replenishment of the budgets of extra-budgetary funds.

The sustainable development of the region is directly related to ensuring its tax security. This necessitates predicting the onset of unfavorable situations (risks), as well as a practical 
assessment of the influence of factors that form the main threats to tax security. The results of such an assessment and the management decisions taken in accordance with it make it possible to level the threats to the tax security of a public law entity.

Recent events in the global economy and health care suggest that there are threats to tax security, which were not previously considered either in the research of scientists, or were defined as risky in legislative acts by the state. The coronavirus pandemic has forced all states to take radical measures to protect their populations: border closures, self-isolation, quarantine and others. These measures have a significant impact on the economy. In this connection, the assessment of such an influence received consecration, including in the scientific literature. In the project, the authors analyze the works of both Russian and foreign authors who have studied the problem of interaction between social and economic and legal trends in the impact of the outbreak of cornavirus on the global economy against the background of falling energy prices.

The central thesis of the project is the provision that the assessment of the tax security of the studied region - the Republic of Mari El - against the backdrop of a pandemic should be based on a sectoral analysis of the structure of tax revenues. At the same time, the assessment of the depth of influence of the measures taken on the stability of the budget system should be based on reasonable indicators characterizing the dynamics of changes in tax revenues. The methodology presented in the project is based on the following stages: 1) sectoral analysis of the structure of tax 
payments in the region in order to determine the most exposed sectors to the risk of non-payment of tax revenues to the budget system; 2) analysis of the measures taken by the Government of the Russian Federation and the Government of the Republic of Mari El, including the regional ones, in response to the pandemic and their impact on the tax security of the region; 3) selection of indicators of tax security of the region in order to monitor and determine the further strategy of economic development.

Summarizing what has been said, we note that the search for a strategy to ensure the tax security of the region, first of all, should be carried out in the context of solving priority tasks, namely: maintaining the financial stability of industries and sectors of the economy, as well as regional budgets. State support should be preceded by a comprehensive assessment of the economic impact of the imposed response measures. Ensuring tax security of public law education in the face of unforeseen tax risks, the onset of which is a direct threat to the lack of tax revenues for the budget system, at the first stage should be associated with the organization of monitoring indicators to assess the depth of the impact of unforeseen risks. At the same time, the reduction and prevention of such risks (leveling) is the main tool for ensuring the tax security of the region and is based on the choice of a further strategy of economic development.

The sustainable development of the region is directly related to ensuring its tax security. This necessitates predicting the onset of unfavorable situations (risks), as well as a practical assessment of the influence of factors that form the main threats to tax security. The results of such an assessment and the 
management decisions taken in accordance with it make it possible to level the threats to the tax security of a public legal entity.

Recent events in the global economy and health care suggest that there are threats to tax security, which were not previously considered either in the research of scientists or were defined as risky in legislative acts by the state. The coronavirus pandemic has forced all states to take drastic measures to protect their populations: border closures, self-isolation, quarantine and others. These measures have a significant impact on the economy. In this connection, the assessment of such an influence received consecration, including in the scientific literature.

So, the impact of the outbreak of coronavirus on international trade transactions was investigated by S.I. Dolgov. and Savinov Yu.A. (2020). The authors note that the pandemic in the short term will slow down the growth of the global economy. The influence of epidemics on the development of the economy is also studied by A.V. Egorov. (2020). Shikov P.A. (2020) describes the fall of the Russian stock market amid the coronavirus pandemic, and also analyzes "the current economic situation of Russian companies during a period of severe turbulence."

Among foreign studies, the work of Ahani A., Nilashi M. (2020) deserves attention, in which the authors describe the role of social networking sites in the exchange of information between customers and enterprises.

The impact of the outbreak of cornavirus on the global economy against the background of falling oil prices is considered by Albulescu C. (2020), taking into account other macroeconomic 
factors in the works of Fernandes N. (2020), Karabag S.F. (2020), Fetzer T., Hensel, L., Hermle, J., \& Roth, C. (2020), Barua S. (2020), Fornaro L., Wolf M. (2020).

The lack of resilience of the global economy to the new threat caused by the pandemic is highlighted in the study by Leiva-Leon D., Pérez-Quirós G., Rots E. (2020).

Regional implications are discussed in the works of Ayittey, F.K., Ayittey, M.K., Chiwero, N.B., Luo S., Tsang K. P. (2020) for China; Koirala J., Acharya S. (2020) for Nepal; Rani R. (2020).

For industry-specific analysis of tourism, see Yang Y., Zhang H., Chen X. (2020), Jamal T., Budke C. (2020), Khan, N., Hassan, AU, Fahad, S., \& Naushad , M. (2020).

The strategy for further business development against the background of the epidemic is explored in the works of Hudecheck, M., Sirén, C., Grichnik, D., \& Wincent, J. (2020).

Investment opportunities and the search for unique strategies with appropriate risk management in a pandemic era are discussed in Tashanova, Diana and Sekerbay, Ainur and Chen, Danni and Luo, Yuwen and Zhao, Shuyi and Zhang, Qingquan (2020), Gormsen N.J., Koijen R.S.J. (2021).

The evaluation of financial policies in response to the virus crisis is explored by Hafiz, H., Oei, S. Y., Ring, D. M., \& Shnitser, N. (2020), Rae M. (2020).

However, among the existing studies, there are no works that would assess the impact of the pandemic on the tax security of individual territories of the state, taking into account the peculiarities of their socio-economic development. 
The aim of the presented study is to form objective analytical data reflecting the state of economic security in the region through a system of indicators of economic security. The working hypothesis of the study is the provision that the assessment of the tax security of the studied region - the Republic of Mari El - against the background of a pandemic should be based on a sectoral analysis of the structure of tax revenues. At the same time, the assessment of the depth of influence of the measures taken on the stability of the budget system should be carried out on the basis of reasonable indicators characterizing the dynamics of changes in tax revenues.

Let's consider in detail the stages of the proposed technique.

Stage 1 . Sectoral analysis of the structure of tax payments in the region in order to determine the sectors most exposed to the risk of non-payment of tax revenues to the budget system.

In connection with the introduction of measures to prevent the spread of coronavirus infection, a large number of organizations suffered losses, including due to the forced long downtime. The list of the most affected industries is determined by the Decree of the Government of the Russian Federation of April 3, 2020 No. 434. These industries include:

- Transport activities

- Culture, organization of leisure and entertainment

- Physical culture and recreation activities and sports

- Activities of travel agencies and other organizations providing services in the field of tourism

- Hospitality

- Public catering 
- Activities of organizations of an additional entity, nonstate educational institutions

- Activities for the organization of conferences and exhibitions

- Activities for the provision of household services to the population (repair, laundry, dry cleaning, services of hairdressers and beauty salons)

- Activities in the field of health

- Retail trade of non-food products

- Mass media and print production.

In order to assess the depth of the impact of the downtime of enterprises in these industries on tax revenues of the consolidated budget of the region under study, it is necessary to conduct a sectoral analysis of the structure of tax revenues. Consider the data of the consolidated budget of the Republic of Mari El on the sectoral structure of tax revenues. For the analysis, we used open data sources presented on the Official website of the Federal Tax Service of the Russian Federation. An analysis was carried out of data on the collection of taxes and fees during 2020. The dynamics of the receipt of insurance premiums for the same period was analyzed separately. Summarized information is presented in table 1 and table 2 .

It can be noted that for a number of types of economic activities (household services, services of an additional entity, activities in the field of culture and sports), paid insurance premiums exceed the amount of taxes and fees paid. 
Table 1

Receipt of taxes and fees in the budgetary system

Of the Russian Federation by type of economic activity

in the Republic of Mari El, thousand rubles

\begin{tabular}{|c|l|c|c|c|}
\hline & \multicolumn{1}{|c|}{$\begin{array}{c}\text { Type of economic } \\
\text { activity } \\
\text { (selectively) }\end{array}$} & \multicolumn{3}{|c|}{$\begin{array}{c}\text { Information as of: } \\
\text { Report in the form No. 1-NOM }\end{array}$} \\
\cline { 2 - 5 } 2 & $\begin{array}{l}\text { Transport and } \\
\text { storage }\end{array}$ & 230835 & 496364 & 677718 \\
\hline 2 & $\begin{array}{l}\text { Activities in the field } \\
\text { of culture, sports, } \\
\text { leisure and } \\
\text { entertainment }\end{array}$ & 65772 & 154520 & 208784 \\
\hline 3 & $\begin{array}{l}\text { Activities in the field } \\
\text { of health and social } \\
\text { services }\end{array}$ & 195264 & 424854 & 589278 \\
\hline 4 & $\begin{array}{l}\text { Activities of travel } \\
\text { agencies and other } \\
\text { organizations } \\
\text { providing services in } \\
\text { the field of tourism }\end{array}$ & 1777 & $*$ & 4108 \\
\hline 5 & $\begin{array}{l}\text { Hospitality and } \\
\text { catering }\end{array}$ & 38612 & 71335 & 93673 \\
\hline 6 & $\begin{array}{l}\text { Additional } \\
\text { educational services }\end{array}$ & 22029 & $*$ & 56635 \\
\hline
\end{tabular}


End of table 1

\begin{tabular}{|c|c|c|c|c|}
\hline & \multirow{2}{*}{$\begin{array}{c}\text { Type of economic } \\
\text { activity } \\
\text { (selectively) }\end{array}$} & \multicolumn{3}{|c|}{$\begin{array}{c}\text { Information as of: } \\
\text { Report in the form No. 1-NOM }\end{array}$} \\
\hline & & 01.04 .2020 & 01.07 .2020 & 01.09 .2020 \\
\hline 7 & Domestic services & 17564 & 35823 & 50011 \\
\hline 8 & Retail & 208080 & 458912 & 671958 \\
\hline 9 & $\begin{array}{l}\text { Information and } \\
\text { communication } \\
\text { activities }\end{array}$ & 116669 & 254550 & 330111 \\
\hline 10 & $\begin{array}{l}\text { Total for all types of } \\
\text { economic activity }\end{array}$ & 6420666 & 11448275 & 15220508 \\
\hline
\end{tabular}

Source: compiled by the authors on the basis of official data from the reports of the Federal Tax Service of the Russian Federation in the form No. 1-NOM. The data is shown on an accrual basis. Note: * information for the specified period is not presented in open data.

Table 2

Receipt of insurance contributions to the budgetary system Of the Russian Federation by type of economic activity in the Republic of Mari El, thousand rubles

\begin{tabular}{|l|l|c|c|c|}
\hline & \multirow{2}{*}{$\begin{array}{c}\text { Type of economic } \\
\text { activity } \\
\text { (selectively) }\end{array}$} & \multicolumn{3}{|c|}{$\begin{array}{c}\text { Information as of: } \\
\text { Report in the form No. 1-NOM }\end{array}$} \\
\cline { 2 - 5 } 1 & \multicolumn{1}{|c|}{$\begin{array}{l}\text { Transport and } \\
\text { storage }\end{array}$} & 197324 & 409944 & 538362 \\
\hline
\end{tabular}


End of table 2

\begin{tabular}{|c|c|c|c|c|}
\hline & \multirow{2}{*}{$\begin{array}{c}\text { Type of economic } \\
\text { activity } \\
\text { (selectively) }\end{array}$} & \multicolumn{3}{|c|}{$\begin{array}{c}\text { Information as of: } \\
\text { Report in the form No. 1-NOM }\end{array}$} \\
\hline & & 01.04 .2020 & 01.07 .2020 & 01.09 .2020 \\
\hline 2 & $\begin{array}{l}\text { Activities in the field } \\
\text { of culture, sports, } \\
\text { leisure and } \\
\text { entertainment }\end{array}$ & 107131 & 203966 & 262695 \\
\hline 3 & $\begin{array}{l}\text { Activities in the field } \\
\text { of health and social } \\
\text { services }\end{array}$ & 388155 & 853735 & 1190756 \\
\hline 4 & $\begin{array}{l}\text { Activities of travel } \\
\text { agencies and other } \\
\text { organizations } \\
\text { providing services in } \\
\text { the field of tourism }\end{array}$ & 2238 & $*$ & 4438 \\
\hline 5 & $\begin{array}{l}\text { Hospitality and } \\
\text { catering }\end{array}$ & 48610 & 75835 & 92514 \\
\hline 6 & $\begin{array}{l}\text { Additional } \\
\text { educational services }\end{array}$ & 41984 & $*$ & 112092 \\
\hline 7 & Domestic services & 32857 & 58181 & 74959 \\
\hline 8 & Retail & 177688 & 305912 & 390583 \\
\hline 9 & $\begin{array}{l}\text { Information and } \\
\text { communication } \\
\text { activities }\end{array}$ & 70592 & 127407 & 167608 \\
\hline 10 & $\begin{array}{l}\text { Total for all types of } \\
\text { economic activity }\end{array}$ & 4491640 & 8917153 & 11794488 \\
\hline
\end{tabular}

Source: compiled by the authors on the basis of official data from the reports of the Federal Tax Service of the Russian Federation in the form No. 1-NOM. The data is shown on an accrual basis. Note: * information for the specified period is not presented in open data. 
The amount of insurance premiums is calculated on the basis of data on the organization's wage fund (or the wage fund for employees of an individual entrepreneur), that is, it does not depend on the revenue and profit of an enterprise or an individual entrepreneur.

In the event of a decrease in entrepreneurial activity as a result of state anti-epidemiological restrictions, business entities find themselves in a situation where they pay wages and insurance premiums against the background of a decrease in revenue and profit. The next step is to assess the depth of the impact of the government's response to the pandemic.

Stage 2. Analysis of the measures taken by the Government of the Russian Federation and the Government of the Republic of Mari El, including the regional ones, in response to the pandemic and their impact on the tax security of the region.

Let us analyze the dynamics of infection in the territory of the Republic of Mari El. As the analysis shows, the number of infected is growing daily, while there is no movement towards stabilization. This suggests that the lifting of the restrictive measures introduced on March 30 is inappropriate. Consequently, the downtime of many businesses continued until mid-July, and a number of restrictions continue to this day. Its impact needs to be assessed taking into account the impact of the measures taken by the government.

A preliminary analysis shows that the greatest threat to the tax security of the region is constituted by the tax revenues not received by the budget from the organizations listed in the table that have suspended their activities. At the same time, in the 
aggregate, tax revenues from them amount to about $10 \%$. If we assume that their downtime will last until the end of May, then the decrease in tax revenues can be estimated at $20 \%$ compared to the same period last year.

Stage 3. Selection of indicators of tax security of the region in order to monitor and determine the further strategy of economic development.

Among the indicators of the tax security of the region, for the purpose of monitoring, we propose to study the following indicators, the state of which affects the choice of a strategy for the economic development of the region:

\section{Tax revenues}

It is necessary to analyze the receipts of tax revenues (in the context of receipts to the consolidated budget of the Russian Federation, as well as to the consolidated budget of the Republic of Mari El) as of April 1, 2020, May 1, 2020, June 1, 2020 in comparison with the same periods of previous years. Particular attention should be paid to the study of tax revenues, which have the largest share in the consolidated budget of the Republic of Mari El. These taxes with a share of more than $80 \%$ include corporate income tax and personal income tax. The analysis should be carried out on the basis of the monthly published reports of the tax authorities in the form 1-NM "Report on the calculation and receipt of taxes, fees, insurance premiums and other obligatory payments to the budgetary system of the Russian Federation."

2. Arrears of taxes and duties 
It is necessary to conduct an analysis of tax and levy arrears as of April 1, 2020, May 1, 2020, June 1, 2020 in comparison with the same periods in previous years. Special attention should be paid to the sectoral analysis of debt, including in the context of types of tax revenues. The analysis should be carried out on the basis of the monthly published reports of the tax authorities in forms 4-HM "Report on tax arrears, fees, insurance premiums, penalties and tax sanctions to the budget system of the Russian Federation" and 4-NOM "Report on tax arrears and levies, insurance premiums, penalties and tax sanctions to the budgetary system of the Russian Federation for the main types of economic activity. "

3. Operational statistical indicators characterizing the state of the economy.

These indicators include: consumer price index; industrial production index; commissioning of residential buildings; retail trade turnover.

The choice of the listed indicators is primarily due to the fact that their assessment is carried out monthly by public authorities, and the data themselves are open. In this connection, they can be considered operational and relevant. It should also be noted that the existing sets of indicators for assessing the impact of coronavirus, including on the economy as a whole, are almost impossible to project onto some constituent entities of the Russian Federation.

For example, Rani R. (2020) proposes to use 5 indicators for such an assessment, which include: consumer spending, the hotel sector, box office receipts in cinemas, the theater industry, and 
consumer confidence. At the same time, tax revenues received by the budgetary system from the activities of hotels in 2019 in the Republic of Mari El amounted to about 0.5\%, organizations of culture, sports and entertainment - about $1 \%$. Consequently, the downtime of these enterprises for three to five months (based on expert estimates, quarantine measures will last for this period of time) will not greatly affect the consolidated budget of the region under study.

If we approach the assessment of tax revenues of the consolidated budget based on their dependence on the indicators of GDP and GRP, then one cannot deny a decrease in tax revenues against the background of a fall in these indicators. According to the Center for Macroeconomic Analysis and Short-Term Forecasting ${ }^{1}$ (CMASF), the fall in real GDP in the optimistic scenario will be able to keep at the level of $2.3-2.5 \%$ in 2020 and $0.5-0.8 \%$ in 2021 . Thus, in two years the economy will contract by 2.8-3.3\%. There are also less optimistic forecasts. Thus, the chairman of the Accounts Chamber, Alexei Kudrin, predicts a 7$8 \%$ decline in GDP. Given the direct relationship between GDP and tax revenues, it can be assumed that the latter will decline in the same proportions.

4. The ratio of taxes and fees paid to the amount of paid insurance premiums. As noted above in our work, the preservation of positive dynamics in the payment of insurance premiums against the background of a decrease in entrepreneurial activity can negatively affect entrepreneurial

\footnotetext{
1Operational monitoring of social processes. URL: http://www.forecast.ru/default.aspx.
} 
activity and the prospects for further business development. The predicted consequences of this situation are the growth of unemployment, since entrepreneurs cannot ensure the payment of wages and payment of insurance premiums in the context of a reduction in entrepreneurial activity. According to Maristat ${ }^{2}$, in comparison with the beginning of 2020 , there is a decrease in the number of people employed at enterprises of such types of economic activities as hotels and catering establishments $(-2,8 \%)$, activities in the field of culture, sports, leisure and entertainment $(-3,5 \%)$, provision of other services $(-3 \%)$, and a number of others.

The search for a strategy to ensure the tax security of the region, first of all, should be associated with the solution of priority tasks. These include: maintaining the financial stability of industries and sectors of the economy, as well as regional budgets. At the same time, such support is impossible without assessing the economic effects of the introduced response measures. The monitoring technique developed by the author on the basis of the selected indicators makes it possible to assess the state of tax security in the region. Thus, ensuring the tax security of a public legal entity in the face of unforeseen tax risks, the occurrence of which is a direct threat to the budget system being unsecured with tax revenues, at the first stage should be associated with the organization of monitoring indicators that allow assessing the depth of the impact of unforeseen risks. At the same time, the

2Express information "Average number of employees (without external part-time workers) of organizations of the Republic of Mari El by type of economic activity." Territorial body of the Federal State Statistics Service for the Republic of Mari El (Maristat). URL: https://maristat.gks.ru. 
reduction and prevention of such risks (leveling) is the main tool for ensuring the tax security of the region and is based on the choice of a further strategy of economic development. 


\section{Chapter 2. MONITORING THE TAX SECURITY MANAGEMENT OF THE REGION}

\subsection{Methodological prerequisites for the organizational}

monitoring model for use in the tax security system of the region

The most important financial institution of every state is the tax system. It functions in conditions of the combined interest of the state and society and regulates both economic and social processes taking place in the country. Representatives of the government, by distributing the state budget, manage the economy, namely: allocate funds to stimulate the growth of various areas of the economy, expand social programs (for example, for the least protected segments of the country's population). Competent allocation of the state budget contributes to the efficient use of resources. In this project, the authors reveal the methodological prerequisites for the organizational monitoring model for use in the tax security system of the region.

Since it is rather difficult for the state to influence the economic and social processes in the country, it is of particular importance to competently and comprehensively build the mechanisms of the budgetary and tax system. Taxes are one of the main items for replenishing the state budget, one of the key levers of influence on the development of the economy and society.

Nowadays, more than ever, it is important to maintain a stable tax system, since it is it that is the most effective mechanism 
that influences and controls the country's economy. Unfortunately, the tax system does not always fully meet modern conditions and needs. This is due to the complexity of calculating and paying taxes to the budget, the difficulty of tax accounting and workflow, the great variety and complexity of filling out and submitting reporting forms, the complexity of automation.

Tax regulation is a purposeful influence of the state on the behavior of economic agents through the use of various methods and instruments of tax policy to achieve the desired socioeconomic results. As a result of tax regulation, the state determines the sources of financing of socially necessary costs, realizing the fiscal function of taxes, and also contributes to the restructuring of the economy, the effective implementation of social development tasks. Tax regulation aims to take into account and balance the interests of the state, business entities and citizens.

Tax regulation is recognized as effective if it performs the assigned functions. To do this, it must meet the following criteria:

- to promote regular and optimal tax receipts to the budget in the amount necessary for the state to fulfill its economic, social and socio-political functions;

- contribute to the creation of financial conditions for the resumption of reproduction processes in the economy and society on an expanded basis. Those. to provide such a combination of tax burden and burden, which will allow the participants of the tax system to have, after taxes, funds for the preservation and development of production and reproduction. 
Applying tax regulation measures, the state solves the following tasks:

1. Regulates supply and demand. As a result of solving this problem, there is a change in the structure of direct and indirect taxes, restraining the demand for certain groups of goods by increasing the tax rate or introducing a new tax (excise taxes, taxes inherent in specific economic areas - oil, gas).

2. Forms a rational relationship between accumulation and consumption. As the tax burden decreases, as a rule, savings begin to increase. The same problem can be solved by changing the structure of taxes in favor of taxes on consumption.

3.Affects the rate of inflationary processes. Thanks to taxes, the surplus money supply is withdrawn, but the price level also rises. 4.Influences the formation of a rational sectoral structure. The creation of more lenient tax conditions for enterprises in certain economic sectors contributes to an increase in profitability and an increase in investment attractiveness, and therefore, an accelerated development of the industry as a whole.

5.Stimulates investment and innovation processes. This task is solved by providing a tax investment credit; direct benefits to innovative enterprises; special methods for calculating amortization and taxation of dividends, the introduction of special taxation regimes (within the framework of special economic zones and technology parks), etc.

6. Accelerates the development of depressed areas. The solution to this problem is carried out at the expense of such means of tax regulation as the introduction of special taxation regimes for certain territories, as well as the implementation of regional and 
municipal tax policy by regional authorities and local selfgovernment bodies (whose competence, as a rule, includes not only the introduction and abolition of most regional and local taxes, but also the provision of benefits for national taxes and fees received in regional and local budgets).

7.Increases effective employment and self-employment of the population. Through the introduction of special tax benefits, the creation of simplified taxation regimes, the state stimulates the subjects to "get out of the shadows."

8. Stimulates the development of a competitive environment, which is advisable to carry out in risky market segments from the point of view of antimonopoly legislation.

9.Saturates the market with socially significant goods and services. It is possible to introduce special benefits for consumers or manufacturers of a certain group of goods.

10.It restrains the growth of production volumes of goods, in the increase of consumption of which the state is not interested. By introducing excise taxes and increasing tax rates on goods harmful to consumption (tobacco, alcohol), the state influences the consumption of these goods. The consequence of this is increased competition and a corresponding restriction on the production of such goods.

11.Reduces the anthropogenic load on the natural environment through environmentally oriented taxes and fees, tax incentives for the use of environmental technologies, production of environmentally friendly products, energy conservation and the use of alternative energy sources. 
12.Creates interest in the development of entrepreneurial initiative. To solve this problem, a tax holiday regime, a simplified taxation and reporting system is used. Стимулирует увеличение масштабов деятельности субъектов хозяйствования. Один из интересных способов, который подразумевает установку фиксированного налога, не зависящего от конечного результата деятельности субъекта.

13.Promotes the rational use of natural resources. In a sense, the very introduction of taxes and fees such as water and land taxes, fees for the use of wildlife and aquatic biological resources, and an environmental tax is aimed at solving this problem.

Increases the economic interest of enterprises in innovative development. The problem is solved by establishing targeted benefits for innovative projects, venture capital enterprises, motivation to improve the educational level of employees, interest in scientific and technical activities, etc.

Currently, in the field of taxes and taxation, there are a number of pressing problems that require prompt solutions. One of the problems is the high share of the shadow economy, as well as the use of tax avoidance schemes by taxpayers. This, firstly, contributes to the loss of a significant part of tax revenues to the budgets of various levels, and secondly, it generates unequal competition between economic entities, since companies that fully pay taxes to the budget find themselves in advance in less favorable economic conditions than unscrupulous ones....

State tax regulation is based on tax incentives and tax restraints. The key features of tax incentives are the use of reduced tax rates, the optimal ratio of elements of the tax system 
(in composition and structure), the level of the tax burden and the rates of specific taxes, the use of tax incentives and preventive measures. Tax incentives affect economic actors at all levels: from social processes and taxpayer behavior to the economy as a whole. The most common form of tax incentives is incentives.

The reason for the lesser applicability of tax restraint in comparison with incentives is due to the fact that it limits the growth of certain spheres of economic activity and investment activity. It is mainly used to avoid a crisis of overproduction, which in modern conditions is not typical for the economy.

Ensuring economic security, the state can influence economic and social processes by applying and changing the following tax policy instruments: various types of taxes and rates, tax incentives; the tax burden; excise taxes; import and customs duties; special tax regimes; alternative tax systems; methods of calculating the object of taxation; tax sanctions.

It should be noted that, depending on the results of the impact in the field of taxation, tax regulation instruments of different composition are distinguished. Results of the impact of tax regulation instruments:

1. Increase or decrease in the tax burden. An increase in the tax burden, as a rule, promotes tax evasion, the development of the shadow economy, and may negatively affect the viability of enterprises. At the same time, tax cuts stimulate the revival of all economic processes and reduce the level of the shadow economy, although it can help to reduce budget profitability.

2. Changing the structure of the tax system. As a result of the redistribution of the tax burden between producers / suppliers of 
goods / services and their consumers by introducing or abolishing taxes or tax incentives, the state is able to obtain a certain economic effect.

3. By changing the ratio of direct and indirect taxes, the state can both promote savings and investment, and reduce the motivation to produce and receive income. By influencing the ratio of corporate and individual taxes, it is possible to stimulate business activity, influence the structure of investments, production volumes, real incomes of the population, as well as the level of consumption, prices and competitiveness of entities.

4. Development of alternative taxation systems (taxation system for producers of certain sectors of the economy, simplified taxation system, single tax on imputed income, etc.) Such taxation systems are aimed at stimulating the development of certain areas of the economy and entrepreneurship. The essence of alternative taxation systems is to provide the taxpayer, subject to certain conditions, the possibility of an independent choice of the taxation system, refusal to pay a separate category of taxes and fees.

5. Creation and development of special territorial taxation regimes (the so-called special (free) economic zones (SEZ)). In this case, the problem of economic development of the most promising regions is being solved, which have a high growth potential in a certain economic sphere (recreational, foreign trade, technological, etc.) or equalizing regional development by improving the investment attractiveness of lagging regions, which also contributes to solving the accompanying social problems.

6. Creation and development of special sectoral tax regimes. The effect is due to the application of a set of benefits introduced 
simultaneously for several different taxes and fees, typical for business entities of the same industry or taxpayers carrying out a certain type of activity.

7. Development of mechanisms related to changes in the composition of an object or subject of taxation. The ability to remove certain types of activities or business transactions from the taxable object can help to increase the profitability of the taxpayer's activities.

8. Development of mechanisms related to the procedure for calculating tax liabilities. The volume of the tax burden is influenced by the order and scope of the application of prices; method of tax accounting; the possibility of carrying forward losses of previous years; the possibility of adjusting (increase / decrease) the level of stocks; the possibility of reducing the amount of income tax payable by the amount of the cost of paying other taxes.

9. Development of preferential programs. A characteristic feature of incentives is selective provision based on meeting certain criteria.

However, it should be noted that the tax impact on business entities is also manifested in the establishment of sanctions for tax violations. Legal responsibility in the doctrine has always been identified with the form of ensuring the proper performance of an obligation. The establishment of tax liability indirectly affects the legal consciousness of subjects of tax legal relations, warning them of the negative consequences of violation of the rule of law.

Methods are subdivided depending on the form of their implementation. So, direct and indirect forms are distinguished. 
Direct forms of tax regulation imply administrative mechanisms of influence on subjects, namely through the establishment of prohibitions, prescriptions and permissions. Obviously, the imperative form alone is not enough to achieve the effectiveness of tax policy. For the complexity of regulation, it is necessary to combine administrative forms with indirect economic ones. With the help of economic forms, the state creates conditions for increasing the activity of taxpayers or for refusing to carry out certain types of activities. These forms include the provision of an investment tax credit, incentives, etc.

Currently, there is an active modernization of the Russian tax system, there is a search and implementation of the most effective tax instruments capable of creating an effective investment-oriented economy that ensures the economic security of the regions.

According to the "Main directions of budgetary, tax and customs-tariff policy for 2021 and for the planning period of 2022 and 2023", the following priority areas can be identified, which create the foundation for monitoring tax security:

1. Balanced reduction of direct taxes (especially for small and medium-sized enterprises (SMEs);

2.Effective provision of tax incentives for oil production (cancellation of incentives for extraction from already depleted subsoil, granting incentives for the development of new promising fields);

3.Equitable distribution of costs for the use of resources in the extraction of minerals; 
4.Deoffshorization of the Russian economy, which implies a reduction in the gap between the taxation of income of domestic capital and "offshore" (increase in the tax rate on income received in the territory of "offshore"; revision of taxation conditions in order to avoid double taxation with neighboring jurisdictions; introduction of taxation of passive income from investment results in bank deposits, debt securities);

Reducing insurance premiums for SMEs;

1. Expansion of the criteria for the possibility of transition from the UTII regime to the patent taxation system (PSN);

2. Extension of the possibility to introduce a "tax vacation" regime on the territory of individual subjects until 2024;

3. Reducing the list of reporting documents that must be provided to individual entities for the purpose of tax control;

4. Introduction of a flat tax for tax residents with higher incomes with the provision of an option not to declare income;

5. Clarification of the list of income received from sources of the state;

6. Development of tax legislation in the field of digital currency;

7. Ensuring compliance of legislation on international automated information exchange with the OECD Unified Reporting Standard;

8. Improving the quality of financial data exchange;

9. Development of concepts of beneficial ownership of income;

10. Leveling the possibility of avoiding taxation at the international level; 
11. Improving the efficiency of tax administration (increasing the coverage of electronic document flow; simplifying the requirements for entities to enter the tax monitoring system; simplifying the fulfillment of obligations to pay taxes - in one document, without specifying details; improving the quality of interaction between regulators of the tax system);

12. Creation of the institution of electronic bank guarantee to ensure ease of access and improve security;

13. Expansion of the digitization of the spheres of tax regulation.

As world experience shows, tax regulation is more effective when it combines measures to collect taxes (increasing the tax burden) and measures to reduce the tax burden (for example, as a result of expanding partnerships).

At the same time, tax regulation is the most socially expressed branch of managerial actions. Deficiencies in tax regulation contribute to a sharp decrease in tax revenues to the budget, increase the likelihood of violations of tax legislation, increase the conflict of interests of the budgets of the regional and federal levels, and, ultimately, can aggravate the social situation. Tax regulation should contribute to the emergence and maintenance of mutual respect between participants in tax legal relations.

Summarizing what has been said, we note that the search for a balanced combination of the composition and structure of taxes, the volume and structure of the tax burden and tax rates is becoming increasingly important for state tax regulation. It is very important to strike a balance between price, fiscal and regulatory 
functions. How much the built tax system will be optimal and rational depends on its internal structure (it must be economically justified). The decisive role is played by the values of tax rates and tax bases.

Most often, the state uses the following methods of tax regulation:

- impact on the composition and structure of the tax system;

- transition from one method or form of taxation to a more optimal one;

- introduction of a scale of values of tax rates, depending on certain criteria and goals;

- transformation of tax benefits and discounts, their redistribution depending on objects, payers, and directions;

- reduction of the tax rate or full exemption from tax payment;

- providing the opportunity to make a payment after the end of the grace period and write off tax arrears;

- the abolition of the scope of distribution of taxes.

Currently, bills are being implemented, the purpose of which is to update the tax system into a more rational one that meets modern realities.

The improvement of the tax regulation mechanism aimed at rationalizing tax payments and harmonizing tax relations between all their participants can be carried out exclusively on the basis of an effective state tax policy, and only in this case it will become the basis of the tax security of the region. 


\subsection{Consumption taxes in international classifications}

Harmonization of tax systems of different states is impossible without comparing indicators for tax groups. This leads to the study of existing approaches to the international classification of taxes and fees. The project focuses on the place of consumption taxes in the existing classifications: the Organization for Economic Cooperation and Development (OECD), the International Monetary Fund (IMF), the System of National Accounts (SNA), the European System of National and Regional Accounts (ESA). In the OECD classification, the author considers in detail two subgroups of consumption taxes: general consumption taxes and taxes on certain goods and services. Trends in the tax structure in the OECD countries are analyzed. The structure of government finance statistics is considered in detail. The project pays special attention to the fact that in the SNA system there is no separate group of consumption taxes. The analysis of the structure of taxes made it possible to identify which taxes in the structure of the SNA can be understood as taxes on consumption. In contrast to previous scientific studies devoted to this topic, the structure of ESA 2010 is revealed. The author noted the compliance of the ESA 2010 version with the SNA. The comparability of international tax classifications is considered, and the author's approach to the criteria for the key differences of the considered tax groups is highlighted: the belonging of direct and indirect taxes to one group; referring social insurance contributions not to a separate type of payment, but to tax receipts; comparability of data of various international 
classifications with each other; detailed structure of tax payments and their grouping. The presented material can open up new perspectives for further research. It will be of interest to those who deal with tax administration problems.

Systematization and scientific substantiation of the grouping of taxes in accordance with homogeneous characteristics is necessary for legislative purposes, as well as for statistical analysis, the results of which will be comparable to each other. As S.G. Pepeliaev, "tax classifications allow us to understand the essence of differences in the grounds of taxation" [S.G. Pepelyaev, 2015). In addition, the grouping of taxes plays an important role in the harmonization of tax systems of different states and the comparison of various indicators. In modern conditions of the fight against coronavirus infection, the unification of institutions, including the institution of taxation, seems to be especially relevant. So, in the works of Tashanova, Diana and Sekerbay, Ainur and Chen, Danni and Luo, Yuwen and Zhao, Shuyi and Zhang, Qingquan (2020), Gormsen N.J., Koijen R.S.J. (2020) makes a strong case for the need to reduce risks and develop tools to manage them. One of these tools is tax classification. A number of authors offer original classifications of income and expenses as part of their own strategies for the development of an economic entity in a pandemic, for example, Hudecheck, M., Sirén, C., Grichnik, D., \& Wincent, J. (2020).

Such comparisons are usually made using international tax and levy classification systems, among which are the following:

-Classification of the Organization for Economic Cooperation and Development (OECD); 
- classification of the International Monetary Fund (IMF);

- classification according to the System of National Accounts (SNA);

- classification according to the European System of National and Regional Accounts (ESA).

Consider the place of consumption taxes in each of them.

Consumption taxes are levied either on the purchase of goods and services to the end user (sales tax, VAT - at the time of the transaction on goods and services), or on transactions between organizations (VAT), or by levying on certain goods or services (excise taxes, customs duties).

In the considered classification, taxes on goods and services (Tax on goods and services) are defined as all taxes levied on the production, production, sale, transfer, rental or delivery of goods, as well as the provision of services or the use of goods, or permission to use goods or exercise activities ${ }^{3}$.

At the same time, there are two groups of consumption taxes: 4

- General taxes on goods and services, consisting of VAT, sales taxes and other taxes on goods and services. It should be noted that VAT is the largest source of tax revenue for OECD countries. The only country that levies retail sales tax instead of VAT is the United States. The peculiarity of this tax also lies in the fact that it is not part of federal taxes, but is established at the state

\footnotetext{
services.htm

${ }^{3}$ OECD statistics. URL: https://data.oecd.org/tax/tax-on-goods-and-

${ }^{4}$ OECD (2013), Revenue Statistics 1965-2012, OECD Publishing, Paris, DOI: http:// dx.doi.org/10.1787/rev_stats-2013-en-fr.
} 
and municipal level5. At the same time, the share of sales tax in the structure of US tax revenues is $7.3 \%$, while the average for OECD countries in 2017 is $22.1 \%$.

- Taxes on specific goods and services, mainly include excise taxes, customs and import duties, as well as taxes on the implementation of certain activities, for example, social contributions taxes on insurance premiums; and taxes on financial services.

Trends in the structure of tax revenues by OECD countries are shown in Figure 3. (1) reducing the share of consumption taxes in the overall structure of tax revenues; (2) consumption taxes are becoming the leading source of tax revenues, especially VAT; (3) the share of specific consumption taxes (excise taxes, customs duties) decreases.

5Consumption Tax Trends 2019 - the United States. URL: https://www.oecd.org/tax/consumption/consumption-tax-trends-unitedstates.pdf: 


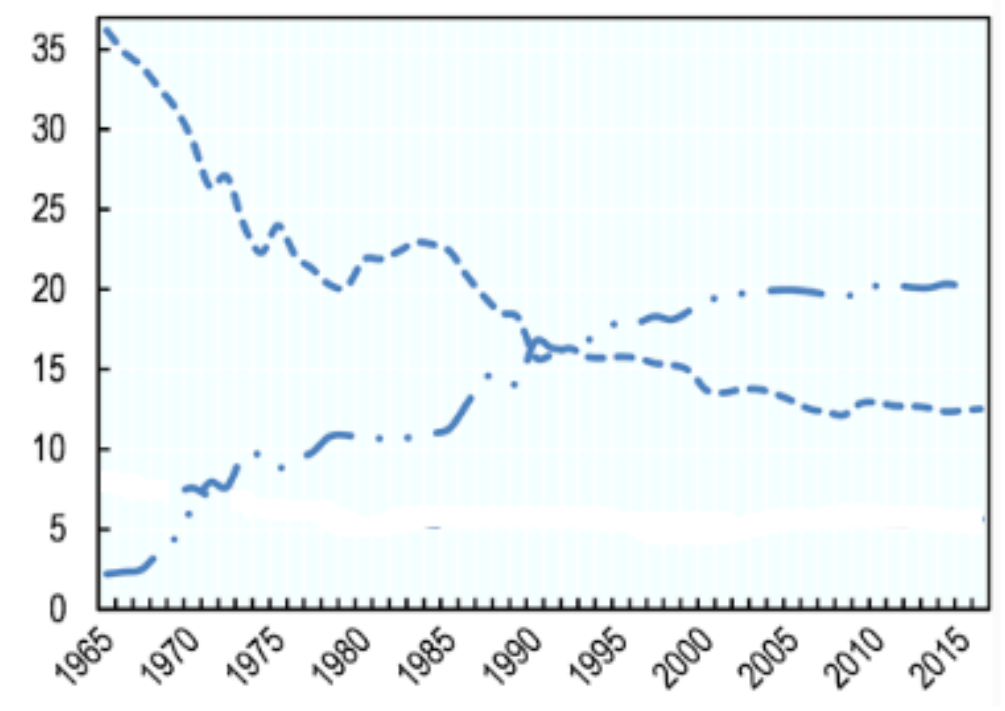

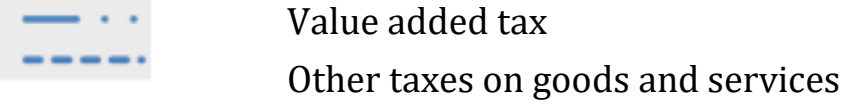

Fig. 3. Trends in the structure of tax revenues

OECD countries in the context of consumption taxes.

Source: Revenue Statistics 2019, OECD Publishing6

Statistical reporting system developed by the International Monetary Fund7 (I.A. Mayburova, Yu.B. Ivanova, 2016), harmonizes the system used for the presentation of tax statistics with other macroeconomic statistical systems, primarily the system of national accounts (2008 SNA), as well as the European System of National and Regional Accounts (ESA 2010).

6OECD (2019) Revenue Statistics 2019, OECD Publishing. DOI: https://doi.org/10.1787/0bbc27da-en.

${ }^{7}$ Government finance statistics manual 2014. - Washington, D.C.:

International Monetary

Fund, 2014. URL: https://www.imf.org/external/Pubs/FT/GFS/Manual/2014/gfsfinal.pdf 
The tax classification found in the IMF manual is similar to that used in the Income Statistics published annually by the OECD. The main difference is that in the OECD statistics, taxes on goods and services and taxes on international trade are combined into a single group.

The structure of government finance statistics in terms of taxes on goods and services is shown in Table 3.

Table 3

Structure of Government Finance Statistics

(Government finance statistics manual 2014)

\begin{tabular}{|l|}
\hline Detailed Classification of General Taxes on Goods and Services (1141) \\
\hline 1141 General taxes on goods and services \\
\hline 11411 Value-added taxes \\
\hline 11412 Sales taxes \\
\hline 11413 Turnover and other general taxes on goods and services \\
\hline 11414 Taxes on financial and capital transactions \\
\hline
\end{tabular}

These taxes are levied on the production, extraction, sale, transfer, leasing or delivery of goods and the provision of services.

The System of National Accounts (hereinafter - SNA) is an internationally agreed standard set of recommendations for the compilation of indicators of economic activity. The SNA describes a coherent, coherent and integrated set of macroeconomic accounts in the context of a set of internationally agreed concepts, definitions, classifications and accounting rules.

In addition, the SNA provides an overview of economic processes, fixes the distribution of products among consumers, enterprises, government and foreign countries. 
The SNA is intended to be used by all countries, as it has been developed taking into account the needs of countries at different stages of economic development.

In the SNA, taxes are compulsory irresponsible payments in cash or in kind made by institutional units to the government exercising its sovereign powers, or to the supranational government. As a rule, they constitute the bulk of government revenues in most countries. Social security contributions, which, while mandatory payments to the public sector, are not included in taxes. ${ }^{8}$

The group of taxes "consumption taxes" is not separately distinguished in the SNA. However, according to the current classification, they can be understood as taxes on products that are levied in proportion to the quantity or value of goods and services produced, sold or imported by residents (I.A. Mayburova, Yu.B. Ivanova, 2016).

These include: taxes such as value added tax; import taxes and duties, excluding VAT; import duties; import taxes excluding VAT and duties; export taxes; product taxes excluding VAT, import and export taxes. At the same time, in contrast to other classifications, taxes on financial transactions (such as taxes on the issue, purchase and sale of securities) are treated as taxes on production, even if there is no provision of services.

It should be noted that the SNA and OECD are based on one classification feature - the object of taxation.

8OECD (2014), National Accounts at a Glance 2014, OECD Publishing, Paris, https://doi.org/10.1787/na_glance-2014-en. 


\section{Classification of the European System of National and}

Regional Accounts (ESA 2010)

The European system of accounts (ESA 2010) [9] is an internationally compatible accounting system used in the member states of the European Union for the unification and structuring of data transmitted to Eurostat. In contrast to the previous version ESA 95, the 2010 system complies with the "System of National Accounts" guidelines (SNA 2008).

According to this classification, taxes on products are a type of taxes on production and imports. Taxes on products (D.21) include the following categories: taxes on products

(1) value added type taxes (D. 211);

(2) taxes and duties on imports excluding VAT (D.212);

- import duties (D. 2121),

- taxes on imports excluding VAT and duties (D.2122);

(3) taxes on products, except VAT and import taxes (D.214);

The last group D.214 includes a large number of taxes and fees. Primarily, this group consists of taxes on goods and services, which are payable as a result of the production, export, sale, transfer, lease or delivery of goods or services, or as a result of their use for own consumption or the accumulation of equity capital. These taxes include, in particular:

- excise duties and consumption taxes;

- stamp taxes on the sale of specific products;

- taxes on financial and capital transactions payable on the purchase or sale of non-financial and financial assets, including foreign exchange (taxes on financial and capital transactions).

- car registration taxes; 
- taxes on entertainment;

- taxes on lotteries, gambling and betting, other than those on winnings;

- taxes on insurance premiums;

- other taxes on specific services: hotels or housing, housing services, restaurants, transport, communications, advertising (other taxes on specific services);

- general sales or turnover taxes (excluding taxes such as VAT): these include general sales or turnover taxes;

- taxes on profits of fiscal monopolies

- export duties and monetary compensatory amounts collected on exports.

These criteria include:

- belonging of direct and indirect taxes to one group;

- referring social insurance contributions not to a separate type of payments, but to tax receipts;

- comparability of data of various international classifications with each other;

- detailed structure of tax payments and their grouping. 


\subsection{Organizational model of monitoring in the context of tax security of the region}

Monitoring as an institution of management and as an object of scientific research has received, in our opinion, fairly wide coverage in the works of a number of researchers. Without dwelling on conceptual analysis, let us note its feature, which forms its interest specifically for our study. Monitoring consolidates analysis, assessment and forecasting, that is, it is a powerful management tool. For tax security purposes, monitoring is valuable as a management tool for collecting and processing data with its subsequent transformation into an adequate management solution.

Monitoring as an institution of the tax security management system of a region includes the activities of authorized entities to form an array of data, that is, phenomena and processes occurring in the country's tax system. Also, the monitoring institution can include activities related to registration of significant data. The quality and completeness of primary data directly affects: the results of the analysis of stakeholders, as well as the results of forecasting in the monitoring system of the tax security of the region. In a global perspective, the quality of primary information and the correctness of its registration and processing will affect the implementation of the main directions of the country's tax policy as a whole.

Highlight the basic requirements for primary information, the observance of which should give guarantees of the reliability 
and objectivity presented for the analysis and management decision-making of the data:

First, it is required to single out the aggregates of the analyzed data without considering individual fragments or elements of one or another analyzed phenomenon. Currently, this requirement can be met by creating a calendar for the delivery of tax reports.

Secondly, the data obtained as a result of observation must correspond to the facts, reflect the real economic and social processes. From the point of view of monitoring in the context of tax security, data registration is carried out on the basis of information from tax returns, which implies their reliability (of course, the problem of dishonest taxpayers when filing a tax return cannot be ruled out either).

Third, the information received, the data for analysis must be comparable in terms of subjects, objects and time. If we are talking about the analysis of data obtained under the general taxation system and special tax regimes, then the comparability of information should be taken into account.

Fourthly, the received data should be subjected to operational processing and analysis so that the decisions made on their basis are relevant and timely.

The collection of data and their processing is carried out within the framework of state statistical observation, including within the framework of tax statistics. Tax statistics is a separate branch of socio-economic statistics that provides accounting for the implementation of the normative taxation of income (property) of legal entities and individuals, the completeness and 
timeliness of taxes. It collects and analyzes the types and objects of taxation (amounts of taxes, rates, terms and methods of their payment).

The task of monitoring is not limited to tracking the movement of funds and the process of replenishing the budgets of different levels. These processes should be dynamically monitored. The tax authorities receive information about tax arrears and budget payments from organizations and the population. Tax revenue statistics are based on the principles of fairness, certainty, convenience, economy. The functions of statistics in relation to the tax system are as follows: 1) collection and registration of data reflecting the processes taking place in the regional economy; 2) analytical processing of the obtained data; 3) identification of patterns in ongoing processes; 4) determination of the study of the influence of external factors on the profitability of budgets of all levels. In our opinion, one more function should be performed, namely: 5) provision of indicative monitoring of tax security.

Thus, the information basis for monitoring is an array of information received by tax authorities as a result of declaration work. In addition, the system of presented indicators underlies the formation of the tax passport of the region at the present time. In our opinion, the existing system performs the functions of collecting and processing information, but does not perform the function of forecasting, which means it cannot be a full-fledged monitoring system in order to ensure the economic and tax security of the region. 
In our opinion, monitoring in the context of tax security should be carried out in the context of the following areas of the functioning of the tax system, supported by tax statistics (Nazarov M.G., 2011):

- analysis of the tax base of taxes and fees and its dynamics depending on macro- and microeconomic trends and changes in tax policy;

- analysis of receipts of taxes and fees in the whole of the Russian Federation and the constituent entities of the Russian Federation, by the levels of the budgetary system, by types of economic activity and by groups of taxes;

- analysis of arrears and arrears on tax payments, penalties and tax sanctions, and their structure by levels of the budgetary system of the Russian Federation;

- analysis of the effectiveness of audit work and applied methods of enforced debt collection and restructuring.

Indicators influencing the results of monitoring and requiring consideration:

- changes in the volume of gross domestic product, the volume of products and services rendered by organizations and entrepreneurs of the basic sectors of the economy, the volume of direct investments in fixed assets;

Indicators on the dynamics of exports and imports of products, trade turnover;

- financial results of the enterprise and organization (consolidated result), the number of profitable and unprofitable enterprises. 
Analysis of certain types of taxes provides for the study of various aspects of financial and economic activities. At the same time, a number of general factors can be identified that affect the size of the tax base.

Among the factors that significantly affect the change in the volume of tax revenues of the state budget, there is a change in tax rates and the size of the tax base. Thus, a factor analysis can be carried out and the absolute and relative change in the volume of tax deductions for each type of tax in the reporting period compared to the baseline can be calculated due to two factors: changes in the volume of the tax base and changes in the tax rate.

The formation of monitoring data is based on: a) regular collection and analysis of information (continuous observation); b) on sample observation data (sample observation).

By the time of registration of a feature, the following types of observation carry a certain analytical potential: a) periodic (interval), during which data collection is carried out in the context of declaring companies; b) continuous (does not depend on the periods of submission of tax reports).

In conclusion, we note that the monitoring institute is a powerful large-scale toolkit for ensuring the tax security of the region, including allowing tracking the dynamics of indicators, identifying the features of the structure of phenomena and priority problems and development sectors. 


\subsection{Monitoring of tax security management of a territory based on a risk-based approach}

Dealing with tax risk is complex and goes in different directions. It covers all subjects of the system: government bodies, business entities. In order for risk management to be effective, it is necessary to develop, implement and implement tools to identify, assess and effectively manage risks. At the moment, the risk management system is just beginning to develop in Russia, and it will take a lot of time and resources to bring it into the required state, capable of meeting the needs of the state and society.

At the moment, the key importance in the management of tax risks is given to the functions of tax monitoring, administration and control. The implementation of these functions is based on the scale of coverage of the subjects and the continuity of monitoring and control.

In the context of globalization and heightened uncertainty for the state, the problem of maintaining and improving the economic and social standard of living of the population is especially acute. To solve the most important tasks, the state needs funding. The main item of replenishment of the state budget is taxes. We often hear about the state budget deficit, which occurs when budget expenditures exceed its revenues. Why is the mismatch formed? One of the reasons is the lack of receipt by the state of tax payments to the budget, when the planned revenues from tax revenues are higher than the actual ones. This is due to the realization of tax risks. 
The concept of tax risk is quite new for modern Russia, nevertheless, the issue of its study is very significant, since the consequences of the implementation of tax risks affect very many areas of activity of both the state as a whole and its individual subjects.

The importance of receiving tax payments by the state budget in full, leveling the negative consequences from the implementation of tax risks determines the relevance of the topic of this abstract work.

Within the framework of the tax monitoring system, the content of the following aspects should be determined: 1) classification of risk factors; 2) ways to minimize tax risks; 3) monitoring of tax risks, tax administration and control, as important stages of tax risk management.

By studying the risks, assessing and classifying them, it is possible to develop effective methods of managing them, which will have a positive effect on the development of all spheres of state activity, and primarily in the economic and social sphere. By building a competent tax risk management system, you can improve the efficiency of the entire system, increase government revenues, which will increase the opportunities for growth and prosperity of the population.

Monitoring is one of the most effective methods of risk management. It is always easier to prevent a threat than to deal with its consequences. In the course of monitoring, the state assesses how the tax system works as a whole, how much tax revenues to the budget correspond to the planned ones, how effective the benefits and sanctions are, what are the results and 
consequences of the introduced changes and reforms in terms of tax legislation, what are the losses from the shadow economy and offshore zones, how much the tax system is competitive and a number of other aspects.

The subjects of monitoring are directly state bodies - the Federal Tax Service, the Ministry of Finance, etc. The object of monitoring is the tax system in general and tax risks in particular. The result of monitoring is one or another management decision designed to improve the efficiency of the tax system.

At the strategic level, monitoring is intended to improve the overall efficiency of the tax system. To do this, it is necessary to achieve the implementation of tactical goals: prompt receipt of information on budget revenues, negative consequences of omissions in legislation, ineffectiveness of the introduced changes, etc.

Information, management, analytical and control functions are inherent in monitoring tax risks.

Thanks to the implementation of the information function, public authorities learn in a timely manner about the work of the tax system and its effectiveness. Control implies fixing the actual values of indicators and their deviations from the planned ones. On the basis of the analysis, the reasons and consequences of the differences between the planned indicators and the actual ones are revealed. Then the managerial monitoring function is implemented, which implies the adoption of a managerial decision.

It should be noted that at the moment, the system for monitoring tax risks in Russia does not have a clear, separate 
regulatory framework and relies primarily on interaction with tax authorities and the Treasury. Monitoring is based on data obtained in the course of tax administration. As a result of tax administration, the state implements the following functions: 1) planning and forecasting; 2) accounting and registration of property and taxpayers; 3) control; 4) analysis; 5) regulation; 6) work with taxpayers.

The central place is occupied by the function of tax control. It should be noted that the use of the analysis of large data arrays - big data - has come into practice. The basis is the risk segmentation of the subjects of the tax system, a wide coverage of control combined with a reduction in field inspections, the possibility of submitting clarifications on previously submitted reports.

An important task of tax control is the settlement of disputes between subjects of tax legal relations at the pre-trial stage - tax audit. A tax audit evaluates the performance of tax authorities, compliance with legislation, and improving the efficiency of the tax system.

Summarizing what has been said, let us highlight the main recommendations for the application of a risk-based approach for organizing effective monitoring. First, the set of factors that determine the risks, in our opinion, should be formed on the basis of an individual approach, depending on the sphere of financial and economic activity of an economic entity.

Secondly, modern conditions dictate the need to take into account the epidemiological situation and the restrictive measures introduced by the state. 
Thirdly, the risk factors included in the analysis should be adequate from the point of view of ensuring the tax security of the region. 


\section{CONCLUSION}

A universal methodology for rating assessment of the tax potential of public law entities has been developed. The proposed methodology for rating assessment of municipalities develops a methodological toolkit for managing tax potential and is the basis for the formation of an Information and Analytical System for rating public law entities, depending on the degree of sustainability of the implementation of tax potential (a potential result of a possible practical use of project results). The rating assessment of the territories of the region - municipal districts and urban districts can be carried out on the basis of calculating the integral indicator, which is the conditional tax potential. For this, a calculation algorithm is used, including the stage-by-stage execution of work. At the first stage, the choice of indicators was made to assess the level of development of the tax potential of a municipal entity, taking into account the sectoral structure of the region and municipal statistics. At the second stage, the identified indicators were grouped to assess the level of development of the tax potential of the territory. At the third stage, the ranking of the groups of indicators according to the degree of significance was carried out on the basis of the developed fundamental scale that establishes the correspondence between the qualitative meaningful description of one group of indicators over another and the quantitative ratio of this superiority (significance), which made it possible to quantitatively measure the superiority in paired comparison of groups. A matrix of pairwise comparisons of 
groups of indicators according to the degree of significance has been built, priorities in the calculation coefficient have been determined. At the fourth stage, weights are determined. At the fifth stage, the indicators of each group were calculated in two aspects: the ratio of the selected indicators to the population size and the calculation of the average growth rate of the selected indicator. At the sixth stage, the ranking of municipal districts (urban districts) was made for each of the indicators. At the seventh stage, a summary indicator was calculated for each group. At the eighth stage, the conditional tax potential (UNP) of the municipal district (urban district) was calculated. At the ninth stage, a rating of municipal districts (urban districts) of the region under study is built. At the tenth stage, the obtained data were clustered. The calculation uses the method of cluster analysis, which is necessary for dividing all municipalities into groups according to the level of development of tax potential. Clustering by the k-average method of the obtained values of the conditional tax potential was carried out using the STATISTIKA 7.0 software product, which made it possible to divide all the obtained data into three groups: with a high UNP value, with an average UNP value, with a low UNP value. The obtained data of cluster analysis can serve as a basis for making management decisions, including for the distribution of subsidies to municipal entities.

2. The main provisions of the concept of tax potential have been formulated, on the basis of which a model for managing tax potential has been built to ensure the tax security of the region. Based on the thesis that the category of the tax potential of the state is dualistic, it can be disclosed from two positions: on the one 
hand, as a predicted value and an object of management, on the other, as the volume of the actual receipt of tax revenues in the budget system, the project team investigated the actual tax potential, which is an object of planned management, information for monitoring and regulating the development of the regional economy. Analysis of such a category as strategic tax potential made it possible to conclude that it acts as a flexible tool for assessing tax revenues for the long term, while there is a need to create an information and analytical system for forecasting tax potential, revealing the influence of all internal and external factors, taking into account possible development scenarios, as well as a reflective framework for the mechanism of their implementation. The formation of strategic tax potential for the short term (1 year) is necessary for forecasting taxes and fees in the system of tax administration of the region and for fulfilling the state task of mobilizing taxes. The tax potential was analyzed from the architectural point of view. Any model is determined by the structure of the elements included in it (architectonics). The architectonics of tax potential is understood as a hierarchical system of interrelated and interdependent elements that make up the tax potential. To build models, it is necessary to choose two approaches: from the position of the taxpayer's resources or from the position of the formation of tax revenues of the budget. The interdependence of the elements of the models of tax potential from the point of view of taxable resources and from the point of view of tax revenues, in the opinion of the project team members, makes it possible to design indicators, on the formation of which the value of the tax potential depends. Tax potential in its broadest 
sense is to ensure the optimal volume of tax revenues, at which the territory can achieve economic equilibrium and sustainable development in a changing tax environment. In a narrow sense, the tax potential should be considered as the maximum possible amount of tax revenues of the budgetary system of a particular territory, obtained in the current conditions for the formation of tax bases through the legislatively established tax mechanism.

The main groups of factors are highlighted: technological, naturalecological, social, value system, political, legal, economic; detailed their structure. In contrast to the existing classifications of factors influencing the tax potential, such groups of factors as "value system" and "social factors" are identified. Certain groups of factors were specified and supplemented: economic factors were supplemented by the factor "globalization processes in the world economy"; the political factors include the level of government, ideology, political situation, tax competition, corruption, tax policy. All factors, depending on their influence on the quantitative and qualitative assessment of the tax potential, are divided into groups. The first group of factors affects the parameters reflecting the quantitative certainty of the degree of impact on the dynamically developing set of taxable resources of the territory. These include: economic, legal and political. The second group of factors affects the parameters that cannot be quantified, but which have a certain impact on the formation of taxable resources in the region: natural-ecological, social, "value system".

3. The main approaches to determining the tax security index of the region have been formulated. The work collective 
understands the tax security index as a specific indicator, formed taking into account the structure of the tax potential and the potential level of its retention within the given "safe" framework, as well as taking into account its positive dynamics. The tax security index, in the opinion of the team members, is a key tool for effective management of tax potential in a comfortable tax environment and maintaining such a state of this environment that ensures the tax security of the region. When the index reaches a certain level, the tax potential is a kind of "safety cushion" for a particular region and its municipal entity, as well as for the state as a whole. This is explained from several points of view:

a) a well-defined structure of tax potential and an effective methodology for planning tax payments, based on the existing state of tax bases, trends in their development, due to an increase in production volumes and business value, is a key information basis for budgetary provision, determined based on possible tax revenues to the budgets of all levels;

b) The efficiency of planning tax payments, in turn, is due to a comfortable tax environment, in which the tax culture of taxpayers is preserved and multiplied, tax risks are reduced and the optimal level of tax burden is achieved, combined with the planned and predicted level of profitability of the taxpayer organization. Such a tax environment can be characterized by a sufficient level of tax security;

c) The formed tax potential requires an assessment of not only the planned and forecast values used in its formation, but also the actual data on the tax revenues of the territory that provide the 
budget, its revenue side. A comparative analysis of the forecast and actual data of the tax potential of a specific territory allows us to identify specific areas of management that require decisionmaking in terms of preventing tax risks and increasing the level of tax security.

4. The main provisions of the strategy of tax security of the region and its municipalities have been developed, taking into account the classification of threats to the tax security of the region and its municipalities. Threats to tax security are understood by the project team as a set of conditions and factors that create a danger for the implementation of tax policy and the formation of tax potential as a result of an increase in the level of tax risks. Tax security risks are unfavorable uncertainties that create conditions and form factors of danger to the interests of the state and territory. The working team presented: a classification of threats to tax security of a territory, risks affecting tax security, and a mechanism for identifying tax security risks of a territory, as well as a model for ensuring tax security, which can be considered universal, applied to any territory: a region or a municipality.

The strategy is based on methods for assessing tax potential, among which the project team identified: 1) factual methods (based on the analysis of facts, statistical data and forecast estimates using various models); 2) heuristic methods (based on research and disclosure of previously unknown, the most used of them is the method of expert assessments); 3) methods of integrated assessment (represent an integrated use of the two previous groups of methods). In the course of the study, it was determined that the forecasting of the tax potential of the region 
should be made on the basis of those taxes, the share of which in the structure of tax revenues of the region does not change or changes insignificantly. The assessment of the uniformity of tax revenues was carried out by analyzing the structure of tax revenues of the consolidated budget of a constituent entity of the Russian Federation using the example of the Republic of Mari El. Correlation-regression analysis revealed the relationship between macroeconomic indicators and tax revenues, built models that describe these relationships. The tax potential of a municipal entity has been investigated in three of its states: its own tax potential, nominal tax potential and the conditional tax potential of the municipal entity. The own tax potential of a municipal entity is understood as the totality of taxes and fees mobilized into the budgetary system in a given territory under the current legislation. The nominal tax potential is considered as its own tax potential, adjusted for the rates of deductions of the corresponding taxes and fees to the levels of the budget system. The notional tax potential is represented by a calculated value used to determine the possible amount of subsidies to territories.

5. The necessity of forming an indicative system of tax security has been proved. The interaction of the main indicators has been determined. Threshold values of tax security indicators have been developed and substantiated. A methodology for assessing the tax security of a territory has been developed, a distinctive feature of which is the distribution of the obtained level according to the "traffic light principle". The interrelation of effective and factor indicators of tax security of municipalities is investigated on the basis of modeling methods and statistical analysis. 
All indicators are divided into 5 blocks: 1 . Indicators characterizing the flow of taxes and fees into the budgetary system 2. Indicators characterizing the state of the tax base of the territory. 3. Indicators characterizing tax arrears. 4. Indicators characterizing the results of tax control. 5. Indicators characterizing the socio-economic situation in the region. Information support for the assessment of indicators has been developed. Among all the available indicators characterizing the receipts of taxes and fees to the budgetary system, only those quantitative indicators were selected that characterize the receipts of taxes and fees to the consolidated budget of a constituent entity of the Russian Federation. These included: tax revenues in total (Indus); corporate income tax (Innp); personal income tax (INDfl); excise taxes on excisable goods (products) produced on the territory of the Russian Federation (IAC); personal property tax (Infl); corporate property tax (Iniorg); transport tax (Ytn); gambling business tax (Inib); land tax (Izn); mineral extraction tax (Indpi); fees for the use of objects of the animal world and for the use of objects of aquatic biological resources (ISJM); state duty (IGP). For each indicator, it is proposed to calculate the indicator that will characterize the receipt of each tax and collection to the budget. These indicators include the growth rate and the collection rate. If the calculated coefficient exceeds the inflation value for the corresponding period, then the indicator is assigned 1 point, in other cases 0 points. If the calculated coefficient exceeds $100 \%$, then the indicator is assigned 1 point, in other cases 0 points. Three indicators were selected as indicators characterizing the tax base: 
the tax base for calculating taxes, the amount of taxes due to the use of benefits, the number of taxpayers. Registers-calculations of indicators have been developed, which should be automated in the AIS "Tax". Three indicators were selected as indicators characterizing tax debt: the growth rate of debt to the budget, the growth / decrease rate of settled debt, and the growth rate of debt that cannot be collected by tax authorities. Two indicators were selected as indicators characterizing the results of tax control: the coefficient of effectiveness of inspections, an indicator of the proportion of additionally accrued amounts of tax payments to the total volume of tax revenues. Three indicators were selected as indicators characterizing the socio-economic situation in the region: GRP, Consumer Price Index, and the tax burden on GRP. Threshold values have been determined for each indicator, maximum and minimum values have been determined for each group. At the next stage of the developed methodology, it is necessary to rank the groups of indicators according to the degree of significance. It is carried out on the basis of the developed fundamental universal scale, which establishes a correspondence between the qualitative meaningful description of one group of indicators over another and the quantitative ratio of this superiority (significance), which makes it possible to quantitatively measure the superiority in paired comparison of groups. A meaningful description of the degree of significance has been formulated. A matrix of paired comparisons was built for the selected groups of indicators. The next step is the calculation of the group's aggregate indicator. The gradation of the level of tax security, calculated in conventional units according to the 
developed methodology, is established on the basis of five possible states: "very high", "high", "medium", "low", "very low". These states are distributed according to the "traffic light" principle. In this case, the red color signals a critically low value, yellow - about the need for enhanced monitoring of indicators, green - about a stable state. On the basis of the proposed methodology, the calculations of the level of tax security for the municipal entities of the subsidized region of the Volga Federal District - the Republic of Mari El were made, and the clustering of the data obtained was carried out. Clustering by the method of kmeans obtained values of the level of tax security was carried out using the STATISTIKA 7.0 software product. The obtained data of cluster analysis can serve as a basis for making managerial decisions, including for the distribution of subsidies to municipal entities and changes in the structure of tax revenues of local budgets.

6. The author's approach to assessing the impact of the coronavirus (COVID-19) pandemic on the tax security of the region has been developed, and the features characterizing this impact for the subsidized region have been formulated. The scientific result is a methodology for assessing the impact of the coronavirus pandemic (COVID-19) on the tax security of the region. The assessment of the impact of the pandemic on the tax security of the subsidized region was studied using the example of the Republic of Mari El. The project considers such a central threat to economic security as incomplete provision of tax revenues at all levels of the budget system. The author's methodology for assessing the impact was developed, on the basis of which a 
sectoral analysis of the structure of tax revenues of the consolidated budget was carried out, the industries most susceptible to restrictive measures of the state were identified, and an approach to assessing the consequences of the introduction of restrictive measures was proposed. Indicators of tax security that are subject to further monitoring are highlighted. Objective analytical data have been formed, reflecting the state of economic security in the region through a system of indicators. The working hypothesis of the study was confirmed - the assessment of the tax security of a subsidized region should be based on a sectoral analysis of the structure of tax revenues. At the same time, the assessment of the depth of influence of the measures taken on the stability of the budget system should be carried out on the basis of reasonable indicators characterizing the dynamics of changes in tax revenues and showing the operational state of the region's economy.

7. The author's approach to improving the directions of development of the methodology for ensuring tax security of the territory in the context of the development of the digital economy has been developed. An algorithm for improving the methodology for ensuring tax security of the territory in the context of the development of the digital economy is proposed. Five main directions of development have been formulated in order to increase the level of tax security of the territory using the tools of digital ecosystems. 1. Blockchain technology. Big data. It has been substantiated that the methodology for identifying and leveling threats to the tax security of a territory should be based on an analysis of the mechanism for using blockchain technologies as a 
tool for its provision, as well as the possibilities of analytical work of the Federal Tax Service of Russia with Big data accumulated in the AIS tax and ASK VAT systems. At the same time, the development of analytical support - the development of methodological tools for assessing indicators of tax security of a territory, should be carried out on the basis of BIG DATA accumulated by tax authorities, contained in information analytical systems, and also obtained as a result of interdepartmental exchange. On the business side, an ecosystem of analytical products for processing Big data is just being formed, as for the state, such a system has in fact already been created. This necessitates the search for new effective directions for the use of existing big data and the development of innovative tools for their processing. 2. Risk assessment and identification of external and internal threats to tax security of the territory in the context of digitalization of tax administration data. 3 . Development of an economic and mathematical model of tax security of the region and its municipalities. It is substantiated that the development should be carried out on the basis of the obtained results of a generalized model of tax security with the determination of the role of its main components in the values of the basic parameters of risks and associated adverse consequences, as well as the construction of scenarios of adverse events and quantitative assessment of risks through the parameters of the main initiating and damaging factors. 4. Development of a strategy for ensuring the tax security of the region, taking into account the identified risks that form the threat of insecurity of budgets with tax revenues. The main components 
of the strategy for the tax security of the territory in the context of the development of the digital economy have been identified and formulated: a) identification of the main trends in the formation and development of Russian tax policy, taking into account the security of a public legal entity in the context of the development of the digital economy; b) analysis of internal and external threats to tax security of a public legal entity; c) development of methodological support and strategy for tax security of the region and its municipalities. 5. Development of an index of tax security of the territory for the purpose of its constant monitoring based on Big data analytics. The author's definition of the category "tax security index" is given, which is an indicator that can be used to assess the state of stability of a public legal entity in order to check the presence of a threat of lack of tax revenues for budgets of all levels. The implementation of the presented improvement algorithm makes it possible to timely identify risk zones, correctly identify threats to tax security, and immediately take measures to ensure an acceptable level of tax security.

8. The role of the subjects of the ecosystem of small and mediumsized businesses as the main sources of sustainability of local budgets in subsidized regions has been substantiated in order to ensure tax security of a public legal entity. The prospects and economic effect of the deployment of comprehensive balanced state support for the ecosystem of small and medium-sized businesses within the constituent entity of the Russian Federation, the Federal District, and Russia in order to ensure the tax security of the territory are scientifically substantiated. A methodological basis for the study has been formed, the use of 
economic and mathematical research methods and analytical tools of a comprehensive system of balanced state support for small and medium-sized businesses has been substantiated, including the creation of its strategy that ensures sustainable socio-economic development. development of the region and its municipalities in search of a balance of the regional ecosystem. An analytical study of the options for using the distributed ledger technology (blockchain) for project tasks was carried out. Analysis of existing information and analytical systems used by government agencies to implement distributed ledger technology. Determination of the optimal technological platform for solving problems of ensuring balanced state support for the ecosystem of small and medium-sized businesses. Analysis taking into account the possibility of practical implementation of the use of smart contracts in the Etherium, Masterchain or Waves blockchain. The basic principles of applying a balanced system of state support for small and medium-sized businesses have been developed.

9. The necessity of applying a risk-oriented approach to tax security management has been proved. The role of the main elements of the tax security management process in terms of the basic parameters of risks and associated damages, which make it possible to assess the state's ability to ensure social obligations in conditions of a budget deficit, has been determined. The management tools were investigated depending on the time of risk manifestation. The author's approach to monitoring in the tax security management system of a public legal entity has been developed. A method for data visualization - building a heat map of risks - was developed and tested on the example of a subsidized 
region with a low level of socio-economic development - the Republic of Mari El. The concept of tax security management for a public legal entity has been developed. The author's approach is based on the classical control functions identified by A. Fayol. The concept is built on the interconnection of three main elements: analysis, monitoring and regulation. The role of analysis in the control system is determined. Special attention is paid to monitoring. The author provides the author's definition of monitoring in relation to the management of tax security as a systematic confirmation that the selected indicators characterizing the budgetary and tax system correspond to the established "corridors". It is proposed to use the method of constructing a heat map as a data visualization tool for monitoring. It is noted that regulation and management decisions should be carried out taking into account monitoring data and the main guidelines of the budgetary and tax policy of a public legal entity. Highlighted the short-term and medium-term provision of tax security management. Analyzed, depending on the time of manifestation of risks, management tools. A subsidized region with a low level of socio-economic development - the Republic of Mari El - was selected as the object of testing the data visualization tool - a heat map of risks. The results of the study of five groups of risks (risks of a fall in the level of tax revenues in relation to the planned indicators; risks of insufficient formation of the tax base and assessment of tax potential; risks of an increase in the level of tax arrears in the region; risks of reducing the effectiveness of tax control; risks of a critical situation in the socio-economic development of the region ) made it possible to conclude that the 
greatest attention, from the point of view of short-term provision of tax security of a public legal entity, deserves the risks of insufficient formation of the tax base and assessment of the tax potential. The practical orientation of the results obtained makes it possible to improve the work of participants in the budgetary process in managing the tax security of a public legal entity on the basis of a risk-oriented approach.

10. The author's approach to the analysis of the tax policy of the subsidized region has been developed. The main directions of the development of the tax system of the subsidized region in order to ensure its tax security have been determined.

Theoretical propositions in terms of the formation of a regional tax policy based on the analysis of its constituent elements have been substantiated. The main directions of the development of the tax policy of the subsidized region have been worked out in order to ensure its tax security. The research results have been tested on the example of the Republic of Mari El. The low efficiency of its regional tax policy in comparison with other constituent entities of the Russian Federation has been proved. An assessment was made of the competitiveness of the tax landscape of the region in order to increase the migration of taxpayers to the study area. The content of the elements of the tax policy of the Republic of Mari El is investigated taking into account the current legislation, including the use of SWOT analysis methods. The working hypothesis of the study was confirmed: subsidized regions in terms of the content of the elements of tax policy, which within their competence can be established independently, adhere, in the main, to the policy of maximum taxes, i.e. maximum tax rates have 
been set, and the number of tax incentives has been minimized, while the introduced tax deductions are practically ineffective. It has been substantiated that one of the features of the tax policy of a subsidized region is the search for a balance between achieving fiscal goals, the need to maintain economic growth and ensure social stability. Taking into account the risk-oriented approach to ensuring the tax security of the region, the possible directions of the regional tax policy of the subsidized region are outlined on the example of the Republic of Mari El. The assessment of the impact of individual elements of regional tax policy on the main parameters of the socio-economic development of the region.

11. An organizational model for monitoring the tax security of a public legal entity has been developed. The relationship between the elements of the monitoring structure has been substantiated. Information support for monitoring tax security has been formed.

An organizational monitoring model has been developed, which includes interrelated elements, the implementation of which will reduce the labor intensity of business processes, as well as increase the efficiency of the analytical functions of government bodies that ensure the tax security of the region. The author's approach to monitoring the tax security of a public legal entity as a management institution has been developed: from the standpoint of the activities of state authorities in making management decisions; from the standpoint of the formation (collection), processing and analysis of a large array of data indicators of tax security of a public legal entity. Indicators influencing the results of monitoring and requiring increased attention have been investigated. The author's approach to the 
formation of information support for monitoring tax security is proposed.

12. Based on the accumulated material and the experience of the study, the results obtained in the course of work are visualized within the framework of the public, free information and analytical web portal "Map of tax security of Russia". Scientific and practical result: Information and analytical Internet portal "Map of tax security of Russia". A web portal has been developed, which presents the main scientific results of the team of authors, substantiating the theoretical significance of the study. 


\section{BIBLIOGRAPHY}

\section{Books, collections, monographs}

1. Advisory Commission on Intergovernmental Relations (ACIR). 1982. Tax Capacity of the Fifty States: Methodology and Estimates. Washington, D.C.: U.S. Government Printing Office. URL: http://www.library.unt.edu/gpo/acir/Reports/informa tion/M-134.pdf

2. Ajaz, T. (2010) The Effect of Corruption and Governance on Tax Revenues. T. Ajaz, E. Ahmad. The Pakistan Development Review. 417.

3. Alfirman, L. (2003) Estimating stochastic frontier tax potential: Can Indonesian local governments increase tax revenues under decentralization. Department of Economics, University of Colorado at Boulder, Colorado. Working Paper. №. 03-19. 37 p.

4. Bretschneider, S.I. (1989) Political and organizational influences on the accuracy of forecasting state government revenues. S.I. Bretschneider, W.L. Gorr, G. Grizzle, E. Klay. International Journal of Forecasting. T. 5. №. 3. P. 307-319.

5. Bin, G. (2012) The influence factors on Chinese tax growth of analysis. G. Bin, H.Long-qiang // Management Science and Engineering (ICMSE), 2012 International Conference on. IEEE. 1473-1477. 
6. Berendts, E.N. (2013) Russian financial law. M.: Infra-M, RIOR, 397.

7. Blazhevich O.G. (2015) Financial security of enterprises: determination of the minimum required level. Finance. No. 3 (8). 25-31.

8. Brehm, S. (2013) Fiscal Incentives, public spending, and productivity - county-level evidence from a Chinese province. World Development. Vol. 46. P. 92-103.

9. Blank, I.A. (2014) Financial risk management textbook. Aspect Press, 256.

10. Blank, I.A. (2014) Management of financial security of an enterprise. Elga, Nika-Center, 784.

11. Bogomolov, O.T. (2010) Non-economic facets of the economy: unknown mutual influence: scientific and journalistic notes of social scientists: [collection of articles]. Branch of social sciences RAS; hands. interdisciplinary project and scientific. ed. O.T. Bogomolov, deputy. hands. interdisciplinary project BN Kuzyk. Moscow: INES, 796.

12. Budget and taxes in the economic policy of Russia. Monograph (2018). V.V. Simonov, S.S. Sulakshin, I. V. Podporina, M. Yu. Pogorelko. M.: Scientific expert, 240.

13. Bykovskaya Yu.V., Safokhina E.A. (2019) The Impact of Tax Crimes on Economic Security (In Russian). World Economy: Security Issues, 1, C. 9-14. URL: https://www.elibrary.ru/download/elibrary_3760368 8_74786050.pdf

14. Chen W. (2020) Tax risks control and sustainable 
development: evidence from China. Meditari Accountancy Research. 2020, Vol. 29, No.6., pp. 13811400. DOI: https://doi.org/10.1108/MEDAR-05-20200884

15. Gaponenko, V.F. (2016) Economic security of the enterprise. Approaches and principles. V.F. Gaponenko, A.A. Bezpalko, A.S. Vlaskov. M.: Ed. "Os-89", 208.

16. Gladchenko, T.M. (2015) Economic security of business. T.M. Gladchenko. Actual problems of international relations: Vol. 26. 357.

17. Goryacheva K.S. (2016) The mechanism for managing the financial security of an enterprise: Author's abstract. dis. Cand. econom. Sciences. 17.

18. Goryacheva K.S. (2013) Financial security of the enterprise. Economist. 2013. No. 8. S. 202-216.

19. Galbraith, J. (2008) New Industrial Society; Favorites. J. Galbraith; [trans. from English: A. Alyabyev and others]. Moscow: Eksmo, 1197.

20. Donets L.I. (2013) Economic security of the enterprise. L.I. Donets, N.V. Vaschenko. M.: Center of study. lit., 240.

21. Dergachev, V.A. (2003) Civilizational Geopolitics (Large multidimensional spaces). Scientific monograph. V.A. Dergachev Odessa: IPREEI NASU, 262.

22. Zagorodny A.G. (2015) Financial and economic dictionary. A. Zagorodny, L. Voznyuk. M.: Knowledge, 1079.

23. Zaporozhtseva L.A. (2016) Financial security of the enterprise during the transition to IFRS. International 
accounting. No. 26. 35-47.

24. Ilovaisky, S.I. (1904) Financial Law Textbook. [Works] SI Ilovaisky, and. d.e.-ord. prof. Novoros. un-that. 4th ed. Odessa: type-chromo-lit. A.F. Sokolovsky, VIII, 383.

25. Imam, P.A. (2007) Effect of Corruption on Tax Revenues in the Middle East. P.A. Imam, D.F. Jacobs. IMF Institute and Fiscal Affairs Department. (IMF Working Paper No.07/270). 36.

26. Gupta, M.S. (2002) Governance, corruption, and economic performance. M. S. Gupta, G.T. Abed // International Monetary Fund. 564.

27. Kantorovich L.V. (2011) Mathematical and economic works. Novosibirsk: Nauka, 2011. 760.

28. Kirichenko A., Kim Yu. (2014) Influence of inflationary processes on the financial security of an enterprise. Innovations. No. 1. 220-238.

29. Konobeeva, E.E. (2015) Research and trends of the banking services market in Russia. E.E. Konobeeva, O.E. (2015) Konobeeva. Fundamental Research. № 2 (part 7). 1441-1445.

30. Konobeeva, E.E. (2015) Financial mechanisms for managing business holding structures. E.E. Konobeeva, O.E. Konobeeva, N.I. Lygina (2014). Bulletin of OrelGIET 2014. № 2 (28). 25-29.

31. Konobeeva, O.E. (2015) The influence of the results of the analysis of the financial condition on the credit potential of the enterprise. Konobeeva, E.E. Konobeeva. Fundamental Research. No. 4. 208-212. 
32. Knyazev, V.G. (2010) Tax administration in a transitional economy. V.G. Knyazev.M.: Walters Kluver, 432.

33. Kondratiev, N.D. (2002) Great business cycles and the theory of foresight. Selected works. N.D. Kondratiev; International fund N. D. Kondratyev and others; Ed. call.: Abalkin L.I. (prev.) and others; comp. Yakovets Yu.V. M.: JSC "Publishing House" Economics ", 767.

34. Leontiev, V. V. (2000) Economic essays. Theory, research, facts and politics: Per. from English M.: Politizdat, 415

35. Lind Y. (2020). The Role and Function of Taxation for Sustainable Economic Recovery Post-COVID-19. Florida Tax Review. 2020, 23(2), pp. 495-498. DOI: https://doi.org/10.5744/ftr.2020.2001

36. Karataev, A.S. (2010) Tax potential of the largest taxpayer and its assessment: theory and methodology: Monograph. A.S. Karataev. Yoshkar-Ola: String LLC, 260

37. Quesnay, F. Physiocrats (2008). Selected economic works. F. Quesnay, A.R.Zh. Turgot, S. Dupont de Nemours. M.: Eksmo, 1200

38. Kuzyk, B.N. (2011) Forecasting, strategic planning and national programming: Textbook. B.N. Kuzyk, V.I. Kushlin, Yu.V. Yakovets. 4th ed., Revised. And additional Moscow: Economics, 644.

39. Kuzmenko V.V. (2005) Institutional approach to the study of tax potential and tax burden. V.V. Kuzmenko, E.A. Efimets. Collection of scientific works of SevKavGTU. Series "Economics", №1. 
40. Kuo, C.Y. (2000) Estimation of Tax Revenue and Tax Capacity. JDI Executive Programs. 08. 34.

41. Keen, M. (2012) International tax competition and coordination. M. Keen, K.A. Konrad. Max Planck Institute for Tax Law and Public Finance Working Paper. 84.

42. Le,T. M. (2008) Expanding taxable capacity and reaching revenue potential: cross-country analysis. T.M. Le, B.Moreno-Dodson, J. Rojchaichaninthorn. World Bank Policy Research Working Paper Series. 38 p.

43. Lü, B. (2012) Tax Revenue Is Likely to Maintain Its Rapid Growth: An Explanation within the Framework of Tax Capacity and Tax Effort. Lü Bingyang, Guo Qingwang. Social Sciences in China Vol. XXXIII. N 1. February. 108126

44. Mattos, E. (2011) Flypaper effect revisited: evidence for tax collection efficiency in Brazilian municipalities. E. Mattos, F. Rocha, P. Arvate. Estudos Econômicos (São Paulo). T. 41. №. 2. 239-267.

45. Malmlöf, T. (2014) Economy, Energy and Sanctions. T. Malmlöf et al. A Rude Awakening. Ramifications of Russian Aggression Towards Ukraine. 71.-80

46. Madera, A.G. (2014) Risks and Chances: Uncertainty, Forecasting and Assessment. A.G. Madera. M.: KRASAND, 448.

47. Marshall A. (2007) Fundamentals of Economic Science. A. Marshall. M.: Eksmo, 830

48. Mayburov, I.A. (2011) Tax theory. Advanced course: a textbook for undergraduates studying in the specialties 
"Finance and Credit", "Accounting, Analysis and Audit". I.A. Mayburov, A.M. Sokolovskaya. M.: UNITY-DANA.

49. Mayburov, I.A. (2013) Tax evasion [Text]: problems and solutions: a monograph for undergraduates studying in programs of the direction "Finance and Credit" and graduate students studying in the scientific specialty 08.00.10 "Finance, monetary circulation and credit". [I. A. Mayburov and others]; ed. I.A. Mayburova, A.P. Kireenko, Yu.B. Ivanova. M.: UNITI, 383.

50. Mayburov, I.A. (2010) Tax policy. Theory and practice [Text]: a textbook for undergraduates studying in the specialties "Finance and Credit", "Accounting and Audit", "World Economy". I.A. Mayburov and others; ed. I.A. Mayburova. M.: UNITI-DANA, 519.

51. Mayburov, I.A. (2012) Tax systems. Development methodology [Text]: monograph for undergraduates studying under the programs "Taxes and Taxation", "Finance and Credit". I.A. Mayburov and others; ed. I.A. Mayburova, Yu.B. Ivanova. M.: UNITI-DANA, 463.

52. Muntiyan V.I. (2014) Economic security. V.I. Muntiyan. M.: KVITS, 464.

53. Mayburov, I.A. (2010) Tax reforms. Theory and practice. monograph for undergraduates studying in the specialty "Finance and credit", "Accounting, analysis and audit". I.A. Mayburov et al. Unity-Dana, 463.

54. Mironov, A.A. (2013) Tax potential of the region: theory and methodology of its formation and assessment: 
Monograph. A.A. Mironov. Yoshkar-Ola: String LLC, 2013. 195.

55. Mironova, O.A. (2008) Tax administration: textbook. manual for students studying in the specialty "Taxes and Taxation". O.A. Mironova, F.F. Khanafeev. M.: Publishing house Omega-L, 2005. 408

56. Mironova, O.A. (2008) Tax administration: a textbook for students studying in the specialty "Taxes and taxation". O.A. Mironova, F.F. Khanafeev. M.: Publishing house "Omega-L", 288.

57. Mironova, O.A. (2013) Tax administration: A textbook for university students enrolled in the profile of the direction "Economics" and specialties "Taxes and Taxation", "Economic Security". [O.A. Mironova, F.F. Khanafeev and others]; ed. O.A. Mironova, F.F. Hanafeeva. 3rd ed. Yoshkar-Ola.: String LLC, 418.

58. Noy, I. (2011) Fiscal storms: public spending and revenues in the aftermath of natural disasters. I. Noy, A. Nualsriю Environment and Development Economics. T. 16. №. 01. 113-128.

59. Tax revenues of municipalities: Scientific and methodological manual (2011) D.V. Kunitsyn [and others]. Novosibirsk, 496.

60. The main provisions of the strategy of sustainable development of Russia (2002) Ed. A.M. Shelekhov. 2002. 161.

61. Papekhin R.S. (2017) Indicators of financial security of enterprises. View of young scientists on economic and 
financial reforms in Russia: Sat. Art. Volgograd: Volgograd scientific. publishing house, 190.

62. Parkhomenko, A.V. (2010) Finance statistics: textbook. A.V. Parkhomenko, A.N. Pchelintsev. Tambov: Publishing house of Tamb. state tech. University, 80.

63. Paskachev, A.B. (2004) Analysis and planning of tax receipts: theory and practice. A.B. Paskachev, F.K. Sadygov, R. Ya. Sahakyan [and others]; ed. F.K. Sadigova M., Publishing house of legal literature, 232.

64. Perotti, R. (2019) The effects of tax shocks on output: not so large, but not small either. Working Paper 16786. URL: http://www.nber.org/papers/w16786.

65. Pechman, J.A. (1982) Federal tax policy. 5d ed. Washington, D.C.: Brookings Institution, 452.

66. Rao, H. (1993) Taxable capacity tax-efforts and forecasts of tax-yield of Indian States/H. Rao// Institute for Social and Economic Change, Bangalore. 165.

67. Paul, A.G. (2011) Budgetary and legal regulation of the formation of budget revenues [Text]: monograph. A.G. Paul. Voronezh: Voronezh State Publishing House. University, 114.

68. Petty, V. (1940) Economic and Statistical Works Vol. I and II. M.: Sotsekgiz, 1940. 324.

69. Pessino, C. Determining countries' tax effort/ C. Pessino, R. Fenochietto // Hacienda Pública Española/Revista de Economía Pública. - 195 (2010). 65-87.

70. Pinskaya, M.R. (2004) Fundamentals of the theory of taxes and taxation: Monograph. (Under the scientific 
editorship of Doctor of Economics, Prof. V.S. Barda). M.R. Pinskaya. M.: Publishing house "Paleotype", 2004. 216

71. Reverchuk N.I. (2014) Management of economic security of entrepreneurial structures. N.I. Reverchuk. 195.

72. Ricardo, D. (2008) Principles of Political Economy and Taxation. Favorites. D. Ricardo; [trans. from English; foreword N. Klyukin]. M.: Eksmo, 960.

73. Romer, C.D. (2010) The macroeconomic effects of tax changes: estimates based on a new measure of fiscal shocks. C.D. Romer, D.H. Romer. American Economic Review. 100(3). 763-801.

74. Sahakyan, R.A. (2001) Tax potential of the Russian economy. R.A. Sahakyan. M.: ID Melap, 396

75. Sahakyan, R.A. (2007) Analysis and forecasting of tax revenues. Problems and practice. Sahakyan R.A. M.: IET, 340.

76. Samuelson (1997) Economics: trans. from English V. D. Antonova and others. Samuelson. 5th ed., Add. and revised M.: NPO "ALGON", Mechanical Engineering, 1997 Vol.2. 5th ed., Add. and revised 1997. 415.

77. Sinelnikov-Murylev, S.G. (2011) Corporate profit tax: analysis of the 2001 reform and modeling the tax potential of the regions. S.G. Sinelnikov-Murylev, G.I. Idrisov, A. Kadochnikov. M.: Institute Gaidar, 180.

78. Sosnin A.S. (2017) Business safety management. A.S. Sosnin, Ya. Prigunov. K.: Publishing house of the European University, 504. 
79. Smith, A. (2007) Research on the nature and cause of the wealth of peoples. A. Smith. M.: Eksmo, 960.

80. Strategy 2020: New Growth Model New Social Policy. Final report on the results of expert work on topical issues of Russia's socio-economic strategy for the period up to 2020. Book 1; under scientific. ed. V.A. Mau, Ya.I. Kuzminov. M.: Delo Publishing House, RANEPA, 2013. 430

81. Say, J.-B. (2000) Treatise on Political Economy. J.-B. Say. Economic sophisms; Economic harmony. F. Bastiat [Text]. J.-B. Say. M.: Delo, 229.

82. Fateev, D.I. (2003) Actual problems of forming the tax potential of municipalities. D.I. Fateev. Actual economic problems of the South of Russia. Collection of conference materials. Pyatigorsk Linguistic University. Pyatigorsk, 5-17.

83. Fayol H. (1923) General and industrial management. Translation into Russian: B.V. Babina-Korenya. URL: https://gtmarket.ru/library/basis/5783/5788

84. Khanafeev, F.F. (2008) Analytical support for the management of the tax potential of the region: theory and methodology: Monograph. F.F. Khanafeev. M.: Publishing house "Prospect", 232.

85. Khrapkina V. (2016) Analysis of approaches and methods for determining the financial security of an enterprise. Finance. No. 8.14-22.

86. Shemyakina, M.S. (2013) Methodological support for forecasting the tax potential for personal income tax 
(based on the materials of the Republic of Mari El). M.S. Shemyakina M.: Publishing house "Pero". 144.

87. Shemyakina, M.S. (2019) Assessment of the tax potential of the region and municipalities: theory and methodology. M.S. Shemyakin. Yoshkar-Ola: LLC IPF "STRING", 161.

88. Schumpeter, J. (1982) Theory of economic development. J. Schumpeter. M.: Progress, 1982. 455.

89. Schumpeter, J. (2007) Economic development theory. Capitalism, socialism and democracy. J. Schumpeter. M: Eksmo, 2007. 864.

90. Sobarzo, H. (2004) Tax effort and tax potential of state governments in Mexico: A representative tax system. Helen Kellogg Institute for International Studies. Working Paper № 315. 31.

91. Stamp, J. (1922) Wealth and Taxable Capacity. London: P.S. King ad Son, Ltd., 1922.195 p.

92. Strauss H. et al. (2020) Tax Risk Assessment and Assurance Reform in Response to the Digitalised Economy. Journal of Telecommunications and the Digital Economy. 2020, T. 8., №. 4., pp. 96-126. DOI:10.18080/jtde.v8n4.306.

93. Tanzi, V. (1992) 12 Structural factors and tax revenue in developing countries: a decade of evidence. Open Economies: Structural Adjustment and Agriculture. 267.

94. Tanzi, V. (1999) Governance, corruption, and public finance: An overview. Governance, corruption, and 
public financial management. Manila, Philippines: Asian Development Bank.1-20.

95. Varaks, N.G. (2010) Tax mechanisms of functioning of the agro-industrial complex at the macro and micro levels. Integration of accounting, analytical and tax processes at the macro and micro levels: monograph. At 3 pm Part 2. [L.V. Popov and others]; under total. ed. L.V. Popova. Finpress, 402.

96. Vachugov, I.V. (2003) Taxes and tax potential of the region. I.V. Vachugov. N. Novgorod: Gladkova, 72.

97. Vlasov, D.V. (2001) Tax relations: essence and ways of improvement. Voronezh: VGAU, 122.

98. Vorobiev, S.N. (2013) Risk Management in Entrepreneurship. S.N. Vorobiev. Dashkov and K, 2013. 963.

99. Enterprise Economics. Ed. L.G. Melnik. (2013) M., 638.

100. Enterprise Economics. Ed. S.F. Pokropivny, (2016) Moscow: Finance and Statistics, 528.

101. Economic security of Russia (2015): General course: Textbook. Ed. VC. Senchagova, Moscow: Delo, 896.

102. Yutkina, T.F. (2002) Taxes and taxation: Textbook. for university students studying for econ. specialties. T.F. Yutkina. 2nd ed., Rev. and add. M.: INFRA-M, 574.

103. Yanzhul, I.I. (2002) The main principles of financial science: The doctrine of state revenues. I.I. Yanzhul. M.: "Statut", 555.

104. V.I. Yarochkin Entrepreneur and security (2014) Yarochkin. M.: Expert Bureau, 112. 


\section{Dissertations and abstracts of dissertations}

105. Bobrova, A.V. (2007) Formation of a socially oriented tax system in Russia: author. dis. Cand. econom. Sciences: 08.00.05. Bobrova Olga Sergeevna. St. Petersburg, 17.

106. Borovikova, E.V. (2009) Development of tax and budget planning in the constituent entities of the Russian Federation: author. dis. Dr. econ. Sciences: 08.00.10. Borovikova Elena Vladimirovna. Moscow, 38.

107. Varderesyan, L.V. (2008) Tax planning and forecasting in the taxation system of the Russian Federation: author. dis. Cand. econom. Sciences: 08.00.10. Varderesyan Lusine Vladimirovna. Stavropol, 23.

108. Vasilieva, M.V. (2004) Methods for assessing the tax potential of corporate income tax: author. dis. Cand. econom. Sciences: 08.00.10. Vasileva Marina Vladimirovna. Orel, 22.

109. Vasilieva, M.V. (2010) The system of tax forecasting and planning based on the integration of accounting and analytical procedures at the macro and micro levels: author. dis.Dr. econ. Sciences: 08.00.10, 08.00.12. Vasileva Marina Vladimirovna. Orel, 48.

110. Voskanyan, E.S. (2014) Formation and development of sub-federal tax potential: abstract of thesis. dis. Cand. econom. Sciences: 08.00.10. Voskanyan Emma Sergeevna. Orel, 23. 
111. Volkov, A.A. (2012) Formation and use of tax potential in the region: author. dis. Cand. econom. Sciences: 08.00.10. Volkov Andrey Alekseevich. Saransk, 18.

112. Zherebtsov, A.B. (2007) Management of the formation and development of the tax potential of the region: author. dis. Cand. econom. Sciences: 08.00 .05 (15.); 08.00.10. Andrey Borisovich stallions. Moscow, 28.

113. Zenchenko, S.V. (2009) Formation and assessment of the regional financial potential of sustainable development of the economy of the territory: theory and methodology: author. dis. Dr. econ. Sciences: 08.00.05, 08.00.10. Zenchenko Svetlana Vyacheslavovna. Stavropol, 37.

114. Ismikhanov, Z.N. (2009) Economic and mathematical models for predicting the volume of tax revenues (based on the materials of the Republic of Dagestan): author. dis. Cand. econom. Sciences: 08.00.13. Ismihanov Zaur Namedinovich. Rostov-on-Don, 26.

115. Kalinina, O.V. (2006) Complex methodology for assessing the tax potential of the region: author. dis. Cand. econom. Sciences: 08.00.10. Kalinina Olga Vladimirovna. Ivanovo, 20.

116. Karataeva, G.E. (2009) Methodology and accounting and analytical support of profit management and tax risks of construction organizations: dis. Dr. econ. Sciences: 08.00.12. Karataeva Galina Evgenevna. Yoshkar-Ola, 385.

117. Lobova, Yu. A. (2009) Assessment and forecasting of tax potential: on the example of the Republic of 
Bashkortostan: author. dis. Cand. econom. Sciences: 08.00.10. Lobova Yuliana Aleksandrovna. Moscow, 27.

118. Lyatina, E.V. (2008) Formation and assessment of tax potential in Russia: author. dis. Cand. econom. Sciences: 08.00.10. Lyatina Elena Valerievna. Togliatti, 19.

119. Popenkov, D.R. (2006) Tax potential of the subject of the federation: assessment and forecasting by complex macroeconomic indicators: dis. Cand. econom. Sciences: 08.00.10. Popenkov Denis Rudolfovich Vladivostok, 230.

120. Polyakov, N.F. (2004) Methodology and tools for systemic economic forecasting of industrial production and tax revenues in conditions of uncertainty: author. dis. doc. econom. Sciences: 08.00.05, 08.00.10. Polyakov Nikolay Fedorovich. Nizhny Novgorod, 48.

121. Roshchupkina, V.V. (2007) Improving the methodology for assessing the tax potential of the region: author. dis. Cand. econom. Sciences: 08.00.10. Roshupkina Violetta Viktorovna. Stavropol, 23.

122. Roshchupkina, V.V. (2014) Theory and methodology for a comprehensive assessment of the tax potential of the region: author. dis. Dr. econ. Sciences: 08.00.10. Roshchupkina Violetta Viktorovna. Stavropol, 46.

123. Sahakyan, R.A. (2007) Methodology of analysis and planning of tax receipts in the budgetary system of the Russian Federation: author. dis. Dr. econ. sciences. Sahakyan Ruben Armenakovich. M., 42.

124. Saranova, S.N. (2007) Development of tax potential in the system of state regional policy: author. dis. Cand. 
econom. Sciences: 08.00.05. Saranova Saglar Nikolaevna. Volgograd, 25.

125. Slobodchikov, D.N. (2010) Tax potential in the system of regulation of interbudgetary relations: author. dis. Cand. econom. Sciences: 08.00.10. Slobodchikov Denis Nikolaevich. Yoshkar-Ola, 21.

126. Tolstaya, OV (2010) Tax potential of the region and its development: author. dis.Cand. econom.Sciences: 08.00.10. Tolstaya Olga Valerevna. Moscow, 25.

127. Troyanskaya, M.A. (2007) Planning of tax revenues of the regional budget in the system of budget management: author. dis. Cand. econom. Sciences: 08.00.10. Troyanskaya Maria Aleksandrovna. Orenburg, 18.

128. Khanafeev, F.F. (2008) Methodology and analytical support for the management of the tax potential of the region: author. dis. Dr. econ. Sciences: 08.00.10, 08.00.12. Khanafeev Farid Fayzrakhmanovich. YoshkarOla, 42.

129. Khmelevskoy, V.V. (2013) Modernization of the process of forming the tax potential of the territory: author. dis. Cand. econom. Sciences: 08.00.10. Khmelevskoy Vladislav Vyacheslavovich. Vladikavkaz, 27.

130. Che, A.Yu. (2008) The potential of personal income tax in Russia: author. dis. Cand. econom. Sciences: 08.00.10. Che Andrey Yundeevich. Moscow, 21. 


\section{Periodical materials}

131. Arkhiptseva, L.M. (2007) Tax potential: theoretical and practical aspects of use in planning tax receipts. L.M. Arkhiptseva. Taxes and Taxation. No. 7. 39-46.

132. Alekhin, S.N. (2005) Methodology for assessing the tax potential of the territory. S.N. Alekhin. Russian tax courier. No. 6. 63-68.

133. Bogacheva, O.V. (2000) Tax potential and regional accounts. Finance. No. 2. 29-32.

134. Vasilieva, T.Yu. (2008) Tax potential management as a tool for improving regional tax policy [Text]. T.Yu. Vasilyeva, A.A. Vasiliev. Bulletin of the Chuvash University. No. 3. 307-311.

135. Varaks, N.G. (2011) Methods of tax forecasting of receipts for the agricultural sector. N.G. Varaksa. Economic and humanitarian sciences. No. 7. 79-85.

136. Gorsky, I.V. (1999) Tax potential in the mechanism of interbudgetary relations. I.V. Gorsky. Finance. 1999. No. 6 27-30.

137. Goncharenko, L.I. (2009) Tax risks: theory and practice of management [Text]. L.I. Goncharenko. Finance and Credit. No. 2. 2-11.

138. Demenko, A.E. (2013) Preconditions for the Formation of Socio-Economic Forecasting in the Russian Federation Based on the Apparatus of Artificial Neural Networks. A.E. Demenko, V.F. Islamutdinov. Management of economic systems: electronic scientific journal. 
[Electronic resource]. Access mode: http. uecs.ru.ru.innovacii-investicii.item.2570-2013-11-2911-55-25 (date accessed: 01.06.2019)

139. Dzagoeva, M.R. (2004) Institutional approach to the study of tax potential and tax burden. M.R. Dzagoeva. Bulletin of the Financial Academy. N 1. 5665.

140. Dyadik, N.V. (2009) Tax ability and tax readiness as the basis for assessing the tax potential of the territory. N.V. Uncle. North and the Market: Formation of the Economic Order.No. 3. 145-150.

141. Erko, N.S. (2009) Methodology for determining the tax potential of the region. N.S. Erko. Supplement to the journal Polzunovsky Almanac. №1. 31.

142. Zalutskaya, N.M. (2012) Tax potential as a factor of territorial development. N.M. Zalutskaya. Bulletin of the Buryat State University. № 2. 44-47.

143. Kantemirova, M.A. (2013) Simulation model of the cluster organization of the economic system of the region. M.A. Kantemirova. Fundamental research. №4-2. -FROM. 476-480.

144. Kolomiets, A.L. (2000) Analysis of conceptual approaches and methods for assessing the tax potential of regions. A.L. Kolomiets. Tax Bulletin. No. 2. 3-6.

145. Kovanova, E.S. (2013) Cluster analysis in solving the problem of typology of Russian regions by the level and intensity of internal labor migration. E.S. Kovanova. Bulletin of NSUEU. № 4. 166-175 
146. V. V. Krivorotov (2014) Economic security of the state and regions: textbook. manual for university students studying in the direction of "Economics". V.V. Krivorotov, A.V. Kalina, N.D. Eriashvili. M.: UNITI-DANA, 279-284.

147. Lieva, L.M. (2007) On the issue of the relationship between tax potential and tax regulation in the economy. L.M. Lieva. Economic Bulletin of Rostov State University. Volume 5. No. 3. 156.

148. Men'kova, N. (2006) Methodology for assessing the tax potential of municipalities in the context of the implementation of measures in the field of budget planning. N. Menkova. Municipal Economy. No. 4. 50-58.

149. Mironchenko S. (2007) Methods for assessing the income potential of the budgets of the region and municipalities. S. Mironchenko, A. Terekhov. Microeconomics. T. 5. 31-36.

150. Osipov, S.L. (2010) Variable models for measuring tax potential. S.L. Osipov, E.S. Osipova. Scientific notes of the Komsomolsk-on-Amur State Technical University. T. 2. No. 4. 135-143.

151. Ostapenko, R.I. (2014) Structural modeling in science and education: a brief overview and development prospects. R.I. Ostapenko. Modern scientific research and innovation. No. 9 [Electronic resource]. Access mode: http. web.snauka.ru.issues.2013.09.26311 (date of access: 10.12 .2014$)$. 
152. Popova, G.L. (2014) Classification of formalized methods for assessing tax potential. G. L. Popova. Economic analysis: theory and practice. N 34 (385). 44-55.

153. Prokopenko, R.A. (2007) Concept and role of tax potential in the economic development of the region. R.A. Prokopenko. Modern science-intensive technologies. No. 12. 113-115.

154. Roshchupkina V.V. (2010) Modern concepts of regional tax potential formation. V.V. Roshchupkina. Bulletin of the North Caucasus State Technical University. No. 3. 24.

155. Roshchupkina V.V. (2010) Logical structure of the tax potential of the region. V.V. Roshchupkina. Regional economy: theory and practice. No. 2.137.

156. Sahakyan, R.A. (2004) Tax passport of the region as a tool for planning budget receipts. R.A. Sahakyan. Russian tax courier. No. 4. 70.

157. Savchishin, K.E. (2008) Forecasting the indicators of the fiscal sphere within the framework of the quarterly macroeconomic model QUMMIR. K.E. Savchishina. Scientific works: Institute of National Economic Forecasting RAS. No. 6. 225-241.

158. Sidorova, N.I. (2003) Possibilities of using tax instruments to regulate regional development. NI Sidorova. Problems of forecasting. No. 1. 96-107.

159. Tyurina, Yu. G. (2013) Tax climate and tax potential as factors of regional economic development. Yu. G. Tyurina. Economics and Management: scientific and practical journal. No. 6 (116). 51-57. 
160. Khanafeev, F.F. (2008) Analysis in the tax administration system. F.F. Khanafeev. Economic Sciences. No. 1 (38). 363-366.

161. Khanafeev, F.F. (2008) Institutional approach in substantiating tax categories. F.F. Khanafeev. Tax policy and practice. No. 7.1. 41-43.

162. Khanafeev, F.F. (2008) Logical structure of tax potential and substantiation of factors influencing its development. F.F. Khanafeev. Economic Sciences. No. 8 (45). 347-355.

163. Khanafeev F.F. (2009) Management of tax potential in the region: problems and solutions. F.F. Khanafeev, K. R. Mukhametzyanova. Economics. 2009. No. 4. 107-120.

164. Khanafeev, F.F. The influence of state regulation of the economy on the state and assessment of tax potential. F.F. Khanafeev, (2008) Economic Sciences. No. 42. 63-70.

165. Chimitdorzhieva, E. Ts. (2010) Econometric modeling of the tax potential of the region. E. Ts. Chimitdorzhieva. Economic Journal. Issue. 17. 6-13.

166. Chimitdorzhieva, E. Ts. (2009) Complex method of shortterm forecasting of tax revenues of a territory (on the example of the Republic of Buryatia). E. Ts. Chimitdorzhieva. Actual problems of the humanities and natural sciences. 2009. T. 1. no. 7. 143-144.

167. Chimitdorzhieva, E. Ts. (2010) Methods for predicting the tax potential of a constituent entity of the Russian Federation. E. Ts. Chimitdorzhieva. Bulletin of the Russian State University for the Humanities. No. 6. 72-80. 
168. Shalyukhina, M.N. (2001) Tax potential of the region: assessment problems. M.N. Shalyukhina. Tax Bulletin. 2001. No. 1. 31-34.

169. Shemyakina, M.S. (2015) Improving the methodology for calculating subsidies to the budgets of subjects that have achieved the best results in increasing the regional tax potential. M.S. Shemyakina, O.A. Mironova. Bulletin of SamGUPS. № 1 (27). 66-68.

170. Shemyakina, M.S. (2013) Study of the structure of tax revenues of the consolidated budget of the Republic of Mari El. State and municipal administration: modern problems, practice of solutions. Collection of scientific papers based on the materials of the II All-Russian scientific and practical conference: M.: Buki Vedi, 74-76.

171. Shemyakina, M.S. (2013) Conceptual model of planning tax revenues in the budgetary system. M.S. Shemyakina. Economy and entrepreneurship. No. 5 (34). 108-111.

172. Shemyakina, M.S. (2013) Genesis of the category "tax potential". Taxes and taxation. 2013. No. 9 (111). 689704.

173. Shemyakina, M.S. (2014) Indicative planning in the system for assessing tax potential: building a "tree of goals". New University. Series: Economics and Law. 2014.No. 9 (43). 19-21.

174. Shemyakina, M.S. (2014) Methodical tools for assessing tax potential. M.S. Shemyakina, F.F. Khanafeev. Innovative development of the economy. No. 6, part II (24) -2014 November-December. 57-63 
175. Shemyakina, M.S. (2015) Taxable resources as an element of the architectonics of tax potential. M.S. Shemyakina. New University. Series: Economics and Law. No. 2 (48). 27-30.

176. Shemyakina, M.S. (2015) Tax revenues as an element of the architectonics of tax potential. M.S. Shemyakina. Finance and management. No. 1. C.11-19. URL: http. enotabene.ru.flc.article_14531.html Date of access: 10.09.2019.

177. Shemyakina, M.S. (2015) Modeling the tax potential of the region. M.S. Shemyakina. Finance and management. No. 2. 1-43. URL: http. enotabene.ru.flc.article_14544.html -Request date: 09.10.2019.

178. Shemyakina, M.S. (2015) On the issue of factors affecting the tax potential. M.S. Shemyakina. Taxes and taxation. 2015. No. 3 (129). 196-206.

179. Shemyakina, M.S. (2015) Assessment of the tax potential in the system of ensuring the tax security of the region. National security. nota bene. No. 2. 304-311.

180. Shemyakina, M.S. (2015) Methodological support for assessing the tax potential of a municipal formation. M.S. Shemyakina. Taxes and taxation. 2015. No. 7 (133) 474 492.

181. Shulmin V.A. (2013) Socio-economic problems of Russian regions: monograph. V.A. Shulmin. Stary Oskol: TNT, 2013. 132. 
B\&M Publishing

San Francisco, California, USA

Murzina E.A., Shemyakina M.S. (2021). Tax security management of a public entity: monograph, B\&M Publishing, San Francisco. $110 \mathrm{pp}$.

PQN 300

ISBN 978-1-7363817-6-2 